\title{
1 Glial response to hypoxia in trachealess mutants induces synapse
}

\section{2 remodeling}

3

4 Pei-Yi Chen ${ }^{1,2}$, Yi-Wei Tsai ${ }^{2}$, Angela Giangrande ${ }^{3,4,5,6}$, and Cheng-Ting Chien ${ }^{1,2, *}$

5

$6 \quad{ }^{1}$ Institute of Neuroscience, National Yang-Ming University, Taipei, Taiwan

$7 \quad{ }^{2}$ Institute of Molecular Biology, Academia Sinica, Taipei, Taiwan

$8 \quad{ }^{3}$ Institut de Génétique et de Biologie Moléculaire et Cellulaire, Illkirch, France

$9 \quad{ }^{4}$ Centre National de la Recherche Scientifique, UMR7104, Illkirch, France

$10{ }^{5}$ Institut National de la Santé et de la Recherche Médicale, U964, Illkirch, France

$11{ }^{6}$ Université de Strasbourg, Illkirch, France

12 *Corresponding author: ctchien@ gate.sinica.edu.tw (CTC) 


\section{Abstract}

14 Synaptic structure and activity are sensitive to environmental alterations.

15 Modulation of synaptic morphology and function is often induced by signals from

16 glia. However, the process by which glia mediate synaptic responses to environmental

17 perturbations such as hypoxia remains unknown. Here, we report that, in the

18 Drosophila trachealess (trh) mutant, smaller synaptic boutons form clusters named

19 bunch boutons appear at larval neuromuscular junctions (NMJs), which is induced by

20 the reduction of internal oxygen levels due to defective tracheal branches. Thus, the

21 bunch bouton phenotype in the trh mutant is suppressed by hyperoxia, and

22 recapitulated in wild-type larvae raised under hypoxia. We further show that hypoxia-

23 inducible factor (HIF)-1 $\alpha /$ Similar (Sima) is critical in mediating hypoxia-induced

24 bunch bouton formation. Sima upregulates the level of the Wnt/Wingless (Wg) signal

25 in glia, leading to reorganized microtubule structures within presynaptic sites. Finally,

26 hypoxia-induced bunch boutons maintain normal synaptic transmission at the NMJs,

27 which is crucial for coordinated larval locomotion. 


\section{Author summary}

29 Oxygen is essential for animals to maintain their life such as growth, metabolism,

30 responsiveness, and movement. It is therefore important to understand how animal

31 cells trigger hypoxia response and adapt to hypoxia thereafter. Both mammalian

32 vascular and insect tracheal branches are induced to enhance the oxygen delivery.

33 However, the study of hypoxia response in the nervous system remains limited. In this

34 study, we assess the morphology of Drosophila neuromuscular junctions (NMJs), a

35 model system to study development and function of synapses, in two hypoxia

36 conditions, one with raising wild-type larvae in hypoxia, and the other in the

37 trachealess (trh) mutant in which the trachea is defective, causing insufficient oxygen

38 supply. Interestingly, glia, normally wrapping the axons of NMJs, invade into synapse

39 and trigger $\mathrm{Wg}$ signals to reconstitute the synaptic structure under hypoxia. This

40 synaptic remodeling maintains the synaptic transmission of synapse, which associate

41 the locomotor behavior of larvae.

42 


\section{Introduction}

Animals need oxygen and food, not only to sustain life, but also for motility. In vertebrates, oxygen and nutrients are delivered through the vascular systems to organs and tissues throughout the body. To maintain proper nutrient and oxygen supply, and thus physiological functions, the vascular system is also highly coordinated with the nervous system during development. Indeed, the vascular and nervous systems resemble each other in terms of their anatomical structures and developmental processes $[1,2]$. In the brain, nerves and vessels, form close associations and are in physical contact through the third player astrocytes to form neurovascular units (NVU) [3]. Such organization is essential for controlling oxygen and glucose delivery through the blood vessels by neuronal activity, and this regulatory process is mediated through the coupled astrocytes [4]. However, some invertebrates lack the complex vascular systems [5]. In nematodes, oxygen is supplied simply by ambient diffusion to inner cells [6]. Insects such as Drosophila have evolved a prototype of the tracheal system to deliver oxygen and a primitive vascular system, the dorsal vessel, to facilitate nutrient delivery [7]. However, the physical association of nerves, trachea, and glial processes has also been demonstrated at the NMJs of adult Drosophila flight muscles [8].

Animals respond to changing oxygen levels by altering their oxygen delivery system. Insufficient oxygen levels (hypoxia) activate a broad range of genes to reestablish body homeostasis. One crucial regulator of these hypoxia-responsive genes is the sequence-specific DNA-binding transcription factor hypoxia inducible factor 1 (HIF-1) [9]. HIF-1 consists of $\alpha$ and $\beta$ subunits that form heterodimers [10]. Whereas HIF-1 $\beta$ is expressed constitutively, HIF- $1 \alpha$ protein levels are modulated by oxygen levels [11]. Under normal oxygen conditions (normoxia), oxygen-dependent prolyl 
68 hydroxylases (PHDs) catalyze hydroxylation of a conserved prolyl residue in the

69 central oxygen-dependent degradation (ODD) domain of HIF-1 $\alpha$ [12-14].

70 Hydroxylation of HIF-1 $\alpha$ promotes interaction with Von Hippel Lindau (VHL),

71 which is the substrate recognition subunit of the cullin2-based E3 ubiquitin ligase,

72 leading to HIF-1 $\alpha$ ubiquitination and proteasomal degradation [15]. Under hypoxia,

73 prolyl hydroxylation does not occur, HIF-1 $\alpha$ proteins are stabilized and are

74 translocated from the cytoplasm to the nucleus where they form heterodimers with

75 HIF-1 $\beta$ to activate transcription of target genes $[16,17]$. One major class of target

76 genes encoding the Fibroblast Growth Factor (FGF) is involved in inducing

77 angiogenesis in mammals. In Drosophila, the FGF member encoded by Branchless

$78(B n l)$ induces tracheal branching [18]. When oxygen levels are reduced, oxygen-

79 starved cells express Bnl as a chemo-attractant to guide the growth tracheal terminal

80 branches toward them [19].

81 In addition to adaptations of the respiratory system, the nervous system also

82 responds to hypoxia. Oxygen levels modulate the survival, proliferation, and

83 differentiation of radial glial cells (RGCs) in the human cerebral cortex. Interestingly,

84 physiological hypoxia $\left(3 \% \mathrm{O}_{2}\right)$ induces neurogenesis and differentiation of RGCs into

85 glutamatergic neurons [20]. Hypoxia induces neurite outgrowth in PC12 cells through

86 activation of A2A receptor [21]. Brief exposure to anoxia and hypoglycemia caused

87 axonal remodeling in hippocampal neurons, including presynaptic protrusion of

88 filopodia and formation of multi-innervated spines [22]. Under hypoxia or upon

89 depletion of PHD2, upregulation of the actin cross-linker Filamin A (FLNA) induces

90 generation of more immature spines [23]. Astrocytes have been shown to play a

91 crucial role in ischemic tolerance via the activation of $\mathrm{P} 2 \mathrm{X} 7$ receptors, which trigger

92 upregulation of HIF-1 $\alpha$ [24]. 
93 Neuronal PAS (NPAS) proteins containing a DNA-binding Per-Arnt-Sim

94 domain function in vascular and nervous system development. In mice, NPAS1 is

95 responsible for cortical interneuron generation [25], whereas NPAS3 is required for

96 adult neurogenesis [26]. NPAS1 and NPAS3 also play key roles in lung development

$97[27,28]$. The homolog of NPAS1/3 in Drosophila, Trachealess (Trh), has been well

98 studied for its involvement in formation of the respiratory tracheal system. Trh is a

99 master regulator of tracheal cell fates, activating gene expression to induce tracheal

100 development $[29,30]$. However, the role of Trh in the development of other tissues,

101 particularly the nervous system, is unknown. In this study, we found altered synaptic

102 bouton morphology at the NMJs of $\operatorname{trh}^{1} / t r h^{2}$ mutants. By performing $t r h-R N A i$

103 knockdown and UAS-trh transgene rescue experiments, we show that $t r h$ is required

104 in tracheal cells for normal bouton formation. Defective tracheal branching in the

$105 \operatorname{trh}^{1} / \mathrm{trh}^{2}$ mutant mimics the effect of hypoxic conditions during larval development,

106 and supplying higher than normal oxygen levels restored normal bouton morphology.

107 We further show that glial cells respond to hypoxia by elevating Wnt/Wg expression

108 to mediate synaptic bouton remodeling through HIF1- $\alpha /$ Sima in Drosophila. Finally,

109 we reveal that this synaptic remodeling maintains normal synaptic transmission and it

110 is required for normal locomotion in larvae. 


\section{Results}

112 trh modulates synaptic bouton formation non-cell autonomously

113 To understand the possible role of Trh in synapse formation, we examined

114 NMJ morphology in the $t r h$ mutants. Since both $\operatorname{trh}^{1}$ and $\operatorname{trh}^{2}$ loss-of-function alleles

115 are homozygous lethal [31-33], we examined the trans-heterozygous $\operatorname{trh}^{l} / t r h^{2}$ mutant

116 that survive to adult stages and compared it to wild-type $\left(w^{1118}\right)$ and heterozygous

$117 \operatorname{trh}^{1} /+$ controls. Synaptic boutons of $w^{1118}$ and $\operatorname{trh}^{1} /+$ NMJs were evenly spaced along

118 the axonal terminals, displaying the typical "beads-on-a-string" pattern (Fig 1A, upper

119 and middle panels, enlarged images at right). Strikingly, the $\operatorname{trh}^{1} / \operatorname{trh}^{2}$ mutant larvae

120 exhibited aberrant NMJ morphology in that their synaptic boutons were small and

121 formed clusters without discernable connections, particularly at the terminals (Fig 1A,

122 bottom panel); a phenotype described as "bunch boutons" [34]. This bunch bouton

123 phenotype in the $\operatorname{trh}^{1} / t r h^{2}$ mutant was detected at a high frequency; $18 \%$ of total

124 boutons were bunched compared to $3 \%$ for $t r h^{1} /+$ and $0 \%$ for $w^{1118}$ (Fig 1B). Of the

$12512 \mathrm{trh}^{1} / \mathrm{trh}^{2}$ NMJs we examined, 11 possessed at least one bunch, with an average of 5

126 bunches per NMJ. Each bunch consisted of 3 to 10 small boutons (mean $=4.3$ ). The

$127 \operatorname{trh}^{1} /+$ larvae exhibited a much weaker phenotype; only 4 of 10 examined larvae had 1

128 or 2 bunches, with an average of 5 small boutons per bunch. We did not observe a

129 bunch bouton phenotype in any of the nine $w^{1118}$ NMJs we assayed (Fig 1B).

130 Although the percentage of bunch boutons in the $\operatorname{trh}^{1} / t r h^{2}$ mutant was greatly

131 increased, total bouton number was only slightly higher than that observed in controls,

132 suggesting that bunch boutons form at the expense of normal ones (Fig 1B). We also

133 assessed the percentage of satellite boutons that are also small ones stemmed from

134 normal-size boutons, and are often observed in wild-type NMJs. We observed some

135 satellite boutons in the $w^{1118}$ control and the $t r h^{1} / t r h^{2}$ mutant, and found no significant 
136 differences between them (Fig S1A). Given the small size and clustering of synaptic

137 boutons in the $\operatorname{trh}^{1} / t r h^{2}$ mutant, we examined whether these bunch boutons express

138 synaptic proteins normally. We found that the synaptic vesicle protein Synapsin (Syn

139 in Fig 1A) was normally distributed relative to control, but the active zone protein

140 Bruchpilot (Brp) was expressed at higher levels in bunch boutons (Fig S1B). The

141 postsynaptic glutamate receptor, as revealed by GluRIIA (Fig S1C) and GluRIII (Fig

142 S1B) signal, as well as dPAK (Fig S1C) were also localized in bunch boutons, which

143 were surrounded by the subsynaptic reticulum protein Dlg (Fig S1D). Thus, although

144 the Brp signal intensity in the $\operatorname{trh}^{1} / t r h^{2}$ mutant was stronger than in the wild-type, the

145 composition of synaptic proteins in bunch boutons was largely similar to that of

146 normal-sized boutons.

147 As trh is expressed in both tracheal and nervous systems during embryonic 148 stages [35], altered bouton morphology in the $\operatorname{trh}^{1} / \operatorname{trh} 2$ mutant could be due to a lack 149 of $t r h$ in neurons, tracheal cells or other cells/tissues. Therefore, we performed trh$150 R N A i$ knockdown by using tissue-specific GAL4 drivers for trachea (btl-GAL4), 151 neurons (elav-GAL4), glia (repo-GAL4), and muscles (MHC-GAL4). We observed a 152 dramatic increase in bunch boutons upon tracheal trh knockdown using btl-GALA (Fig $1531 \mathrm{C}$ and 1D). In contrast, trh-RNAi alone or using elav-GALA, repo-GALA or MHC154 GAL4 failed to replicate the bunch bouton phenotype (Fig 1D).

To further confirm the necessity of tracheal trh for normal bouton formation,

156 we performed a rescue experiment of the $t r h^{1} / t r h^{2}$ phenotype. When we expressed a 157 UAS-trh transgene in the trachea of the $t r h^{1} / t r h^{2}$ mutant upon using the tracheal btl158 GAL4 driver, the bunch bouton phenotype was suppressed (Fig 1E and 1F). Controls 159 bearing only the $b t l-G A L 4$ driver or the UAS-trh transgene still contained the 
160 comparably high numbers of bunch boutons observed in $\operatorname{trh}^{1} / \operatorname{trh}^{2}$ (Fig 1B) or upon

161 tracheal trh-RNAi knockdown (Fig 1D). These results indicate that trh is required in

162 the trachea for normal bouton formation.

163

164 Hypoxia induces bunch bouton formation

165 Apart from specifying the tracheal cell fate, Trh is also involved in the

166 branching of tubular structures during post-embryonic stages [30]. Therefore, we

167 examined the tracheal phenotypes in the $\operatorname{trh}^{1} / \mathrm{trh}^{2}$ larvae and observed an increase of

168 the number of terminal branches in the dorsal branch of the third segment (Fig S2A

169 and S2B). Furthermore, we identified morphological defects such as tracheal breaks

170 and tangles, suggesting structural defects in the $t r h^{1} / t r h^{2}$ larvae (arrows in Fig S2A).

171 Tracheal branching activity is enhanced under hypoxia [18]. Thus, the increased

172 number of terminal branches in $\operatorname{trh}^{1} / \mathrm{trh}^{2}$ could be a compensatory mechanism for

173 defective trachea formation.

174 To understand whether $\operatorname{trh}^{1} / \operatorname{trh}^{2}$ mutant cells are under hypoxia, we used the

175 hypoxia biosensor GFP-ODD, in which the GFP is fused to the oxygen-dependent

176 degradation (ODD) domain of Sima, under the control of the ubiquitin-69E (ubi)

177 promoter [36]. We first confirmed that GFP-ODD signal was low under normoxia

$178\left(21 \% \mathrm{O}_{2}\right)$ and enhanced under hypoxia $\left(5 \% \mathrm{O}_{2}\right.$, Fig $\left.2 \mathrm{~A}\right)$ in wild-type late-stage

179 embryos when tracheal tubules are already formed and functioning [36]. Indeed,

180 enhanced GFP signal was ubiquitous under hypoxia in wild-type embryos, with some

181 pronounced focal GFP signals (Fig 2A, upper row, and Fig S2C). The signal of

182 mRFP-nls, also under the control of $u b i$ promoter as an internal control, remained

183 constant under hypoxia (Fig 2A, bottom row, and Fig S2D) [36]. Quantification of the 
184 GFP/RFP ratio revealed a significant difference between normoxia and hypoxia

185 conditions (Fig 2B). We then examined whether oxygen supply is deficient in the

$186 \operatorname{trh}^{1} / \operatorname{trh}^{2}$ mutant by measuring the GFP-ODD signals. We detected higher GFP-ODD

187 signal under hypoxia in the mutant compared to $w^{1118}$ control (Fig 2A and Fig S2C).

188 The heterozygous $\operatorname{trh}^{1} /+$ presented similar GFP-ODD signal to $w^{1118}$. Quantification

189 of the GFP/RFP ratio also demonstrated a significant increase in GFP-ODD signal in

$190 \operatorname{trh}^{1} / t r h^{2}$ (Fig 2B), supporting that the $\operatorname{trh}^{1} / t r h^{2}$ mutant senses reduced oxygen levels.

191 Thus, formation of bunch boutons in the $\operatorname{trh}^{1} / t r h^{2}$ mutant could be caused by

192 hypoxia. To test this hypothesis, we reared wild-type larvae under hypoxia (5\%) and

193 assessed synaptic bouton morphology at the third instar stage. Consistently, we

194 observed small clustered boutons, mirroring the bunch bouton phenotype, at NMJs

195 (Fig 2C and 2D). Furthermore, when we subjected the $\operatorname{trh}^{1} / t r h^{2}$ mutant to a high

196 oxygen level (50\%), the bunch bouton phenotype was completely suppressed, with

$197 \operatorname{trh}^{1} / t r h^{2}$ NMJs exhibiting normal bouton morphology (Fig 2C and 2D). These results

198 suggest that hypoxia due to the defective tracheal system in the $\operatorname{trh}^{1} / t r h^{2}$ mutant

199 induces the bunch bouton phenotype, and that this phenotype can be suppressed by

200 extra oxygen supply.

202 Glial HIF-1 $\alpha /$ Sima mediates bunch bouton formation

203 HIF-1 $\alpha /$ Sima mediates the response to low oxygen supply [37, 38]. Protein

204 levels of Sima are increased in wild-type Drosophila embryos subjected to hypoxia

205 [39], leading to transcriptional activation of downstream target genes and the 206 induction of tracheal branching [18]. We overexpressed Sima in tracheal cells, 207 neurons, glia, or muscle cells by tissue-specific drivers to investigate which types of 208 cells may play a role in modulating synaptic bouton formation. Overexpressing Sima 
209 in trachea caused embryonic lethality, preventing us from observing NMJ phenotypes.

210 Larvae in which Sima was overexpressed in muscles, neurons, and glia could survive

211 to the third instar stage and we detected a substantial number of bunch boutons upon

212 glial Sima overexpression (Fig 3A and 3B). This result shows that the hypoxia-

213 responding factor Sima is capable of inducing bunch bouton formation when

214 overexpressed in glia.

If glial Sima is the factor responsible for responding to hypoxia in the $\operatorname{trh}^{1} / \mathrm{trh}^{2}$

216 mutant, reducing the Sima level in glia would suppress bunch bouton formation.

217 Accordingly, we expressed the sima-RNAi transgene, which could effectively deplete

218 sima expression (Fig S3A), using repo-GAL4 in the $\operatorname{trh}^{1} / t^{2} h^{2}$ mutant. As our

219 prediction, the bunch bouton phenotype was almost completely suppressed upon glial

220 sima knockdown (Fig 3C and 3D). In controls, $\operatorname{trh}^{1} / t r h^{2}$ mutants carrying only the

$221 U A S$-sima-RNAi transgene or the repo-GALA driver still exhibited large numbers of

222 bunch boutons (Fig 3C and 3D). We also tested whether low oxygen level-induced

223 bunch bouton formation is mediated through Sima in glia. Bunch bouton phenotypes

224 were detected in controls carrying either repo-GAL4 or UAS-sima-RNAi when raised

225 in $5 \% \mathrm{O}_{2}$ (Fig 3E). However, almost no bunch boutons were detected in larvae

226 carrying both repo-GALA and UAS-sima-RNAi when raised in the same low-oxygen

227 environment (Fig 3E and 3F). We also examined Sima protein levels in larvae, and

228 found ubiquitous increases (including in Repo-positive glia) in the $\operatorname{trh}^{1} / \operatorname{trh}^{2}$ mutant or

229 for the control under the 5\% $\mathrm{O}_{2}$ condition (Fig S3B). Thus, glial Sima mediates the

230 hypoxia response in the $\operatorname{trh}^{1} / t r h^{2}$ mutant and in the low $\mathrm{O}_{2}$ condition to modulate

231 synaptic bouton formation. 


\section{Glial Wg remodels bouton morphology}

234 Next, we explored possible signals transduced from glia to neurons in 235 response to hypoxia. The glia-secreted Wingless $(\mathrm{Wg})$ signaling molecule regulates 236 synaptic growth at Drosophila NMJs [40, 41]. Therefore, we examined whether Wg

237 can be induced under hypoxia in the $\operatorname{trh}^{1} / t r h^{2}$ mutant. Wg signal was enriched around 238 the synaptic boutons of wild-type NMJs (Fig 4A), similar to previous reported 239 staining patterns $[40,42]$. Although the pattern of $\mathrm{Wg}$ signal at $\operatorname{trh}^{1} /+\mathrm{NMJ}$ was 240 similar to that of $w^{1118}$, we detected much higher levels of $\mathrm{Wg}$ at $\operatorname{trh}^{1} / \operatorname{trh}^{2} \mathrm{NMJ}$ (Fig $2414 \mathrm{~A})$. Quantification of $\mathrm{Wg}$ immunofluorescence intensities normalized to co-stained 242 HRP revealed a $\sim 3$-fold increase relative to $w^{1118}$ and $t r h^{1} /+$, respectively (Fig 4B).

243 We then examined whether Sima is required for the enhanced Wg expression in the $244 \operatorname{trh}^{1} / t r h^{2}$ mutant. In a $t r h^{1} / t r h^{2}$ mutant carrying repo-GAL4, Wg levels were also 245 increased 3.0-fold relative to the repo-GAL4 control (Fig 4C, 4D). When we reduced 246 sima levels in the $\operatorname{trh}^{1} / \mathrm{trh}^{2}$ mutant by repo-GAL4-driven UAS-sima-RNAi, Wg signal 247 was suppressed to a level equivalent to that in the repo-GAL4 control (Fig 4C and 4D). 248 Interestingly, sima-RNAi knockdown in glia of the repo-GALA control had no effect 249 on the Wg level (Fig 4C and 4D), suggesting that Sima is induced to upregulate Wg 250 expression in the $\operatorname{trh}^{1} / \mathrm{trh}^{2}$ mutant but has no role in basal $\mathrm{Wg}$ expression in the wild251 type. Taken together, we suggest that glial Sima is required for Wg upregulation at 252 the NMJs of the $t r h^{1} / t r h^{2}$ mutant.

253 If glia-secreted $\mathrm{Wg}$ is responsible for bunch bouton induction in the $\operatorname{trh}^{l} / \mathrm{trh}^{2}$ 254 mutant, then glia-specific knockdown of $w g$ in that mutant should suppress bunch 255 bouton formation. Indeed, the bunch bouton phenotype was almost undetectable in the $256 \operatorname{trh}^{1} / \mathrm{trh}^{2}$ mutant also bearing repo-GAL4 and the UAS-wg-RNAi transgene (Fig 4E and 257 4F). In control, bunch boutons were still prominent in the $\operatorname{trh}^{1} / \operatorname{trh}^{2}$ mutant bearing 
258 only $U A S$-wg-RNAi (Fig 4E and 4F). Inactivation of $\mathrm{Wg}$ signaling has been shown to

259 induce unbundled filaments and a reduction of the more stabilized loops upon

260 immunostaining for the microtubule-binding protein Futsch [41, 43]. To show that

261 elevated $\mathrm{Wg}$ signaling remodels presynaptic bouton structure in the $\operatorname{trh}^{1} / \operatorname{trh}^{2}$ mutant,

262 we examined Futsch-labeled microtubules within synaptic boutons and found

263 significantly more Futsch-positive loops within the boutons (Fig S4A and S4B),

264 supporting the elevation of presynaptic Wg signaling. Taken together, these results

265 suggest that $\mathrm{Wg}$ plays a prominent role in the $\operatorname{trh}^{1} / t r h^{2}$ mutant to transduce the

266 hypoxia signal from glia to remodel presynaptic bouton structure.

267 Since glial processes can invade synaptic boutons to match the growth of

268 NMJs [44], we were intrigued to assess whether glia the $\operatorname{trh}^{1} / t r h^{2}$ mutant exhibits

269 morphological change. In a live preparation of NMJs, we found that glial processes

270 invaded the area of synaptic boutons in the $\operatorname{trh}^{1} / t r h^{2}$ mutant, whereas glial processes

271 were comparatively restrained in the control (Fig S4C). Quantification of fluorescent

272 signals of glial process overlaying the synaptic bouton area revealed significantly

273 greater area of overlap in the $\operatorname{trh}^{1} / \operatorname{trh}^{2}$ mutant relative to control (Fig S4D). This

274 increased extent of glial processes in the synaptic area may facilitate signal

275 transduction from glia to synaptic boutons for structural reorganization.

277 Impaired crawling behavior in the trh mutant

278 Given the evident morphological changes at $\operatorname{trh}^{1} / t r h^{2}$ NMJs, we wondered if 279 locomotion is affected in mutant larvae. We observed larvae crawling under free280 movement conditions and found that wild-type control and $\operatorname{trh}^{1} /+$ heterozygous larvae 281 presented smooth crawling paths with an average speed of $\sim 0.5 \mathrm{~mm} / \mathrm{s}$ (Fig $5 \mathrm{~A}$ and 
282 5B), whereas the $\operatorname{trh}^{1} / \mathrm{trh}^{2}$ larva had shorter paths and a slower speed of $0.14 \mathrm{~mm} / \mathrm{s}$.

283 The head turning frequency in $t r h^{1} / t r h^{2}$ was comparable to both controls, not

284 contributing to the slow moving (Fig 5C). Larval crawling is a rhythmic behavior

285 involving a series of periodic strides (S1 Movie) [45-48]. We noticed uncoordinated

286 crawling in $\operatorname{trh}^{1} / t r h^{2}$ larvae, with their posterior body segments failing to follow the

287 rhythmic movement (S2 Movie). We recorded larval forward crawling and

288 constructed kymographs to represent the stride cycle. In wild-type larvae, normal and

289 consistent periodic strides were apparent with regular head and tail displacements (Fig

$2905 \mathrm{D}$, left panel). Similar to the wild-type, head movements of $t r h^{1} / t r h^{2}$ larvae were

291 smooth and periodic, albeit slower. However, tail movements of $\operatorname{trh}^{1} / \mathrm{trh}^{2}$ larvae were

292 abrupt (Fig 5D, right panel). Approximately 70\% of the strides of $\operatorname{trh}^{1} / t r h^{2}$ larvae

293 were uncoordinated (Fig 5E), which might contribute to the slower crawling of the

$294 \operatorname{trh}^{1} / \operatorname{trh}^{2}$ mutant.

295 This uncoordinated stride cycle prompted us to examine the bouton

296 morphology in anterior and posterior segments of $\operatorname{trh}^{1} / t r h^{2}$ larvae. Strikingly, we

297 detected the bunch bouton phenotype in segments A2-A4 of individual $\operatorname{trh}^{1} / \mathrm{trh}^{2}$

298 mutant larvae, whereas bouton morphology in their respective posterior A5 and A6

299 segments was relatively normal (Fig 6A). In fact, we seldom observed the bunch

300 bouton phenotype in posterior segments (Fig 6B). In wild-type larvae, all segments

301 we examined had normal bouton morphology (Fig 6A and 6B). While bunch boutons

302 appeared in A2-A4 segments, the total numbers of boutons were comparable in all

303 segments between wild-type and $t r h^{1} / t r h^{2}$. We further examined whether $\mathrm{Wg}$ signal

304 from glia has any effect on modifying bouton morphology in $t r h^{1} / t r h^{2}$ larvae. Glial

$305 w g-R N A i$ knockdown suppressed bunch bouton formation in the anterior A3 segment, 
306 but had no effect on the morphological phenotype of the posterior A6 segment (Fig

307 6E). Thus, induction of bunch boutons is specific to anterior A2-A4 segments.

308 Given the bunch bouton phenotype in $\operatorname{trh}^{1} / t r h^{2}$ larvae, we assessed basal

309 synaptic transmission properties, firstly at muscle 6 of anterior A3 segments.

310 Amplitude of evoked junctional potential (EJP), as well as the amplitude and

311 frequency of miniature EJP (mEJP), were comparable among controls and $t r h^{1} / t r h^{2}$

312 larvae (Fig 7A-7E). The quantal content, calculated by dividing the EJP amplitude

313 with that of mEJP, were also equivalent (Fig 7F). We then evaluated the synaptic

314 transmission properties of muscle 6 for posterior A6 segments. Although the

315 amplitude and frequency of mEJP and the EJP amplitude in $t r h^{1} / t r h^{2}$ larvae remained

316 similar to controls, we did detect a significant reduction in the quantal content of

317 mutant larvae (Fig 7F). Thus, the impaired synaptic activity of posterior segments of

318 mutant larvae seems to be consistent with their defective stride cycle. 


\section{Discussion}

320 Here, we demonstrate that Trh, a member of the NPAS protein family, non-cell

321 autonomously regulates synaptic bouton formation at NMJs through a hypoxia

322 response from glia. We observed small-sized and clustered boutons, so-called bunch

323 boutons, at the NMJs of trh mutant larvae or larvae reared at low oxygen levels. The

324 abnormal bouton morphology at $t r h$ NMJs could be suppressed by reducing levels of

325 the hypoxia response factor Sima in glia. We further showed that Sima enhanced the

326 Wg signal from glia to cause bunch bouton formation. Although normal synaptic

327 transmission was detected at NMJs located in anterior segments of larvae bearing

328 bunch boutons, reduced synaptic transmission was found in posterior segments

329 lacking bunch boutons of the trh mutant, suggesting that glia-induced bunch bouton

330 formation might be a homeostatic response to restore normal synaptic transmission.

331 Imbalanced synaptic functioning of mutant NMJs might contribute to the

332 uncoordinated stride cycles detected in the trh mutant, slowing larval crawl speed.

333 Thus, we provide a model for studying the glial responses that modulate synaptic

334 remodeling during hypoxia.

\section{Glia play a critical role in response to hypoxia in the trh mutant}

337 Animal cells adapt to hypoxia by triggering the expression of HIF-1 $\alpha /$ Sima, the

338 master transcriptional regulator of the hypoxia response [49]. We observed defective

339 tracheal structure in the trh mutant (Fig S2A), which may result in hypoxic conditions

340 inside the larval body. The increase in terminal branch number (Fig S2B) may be a

341 response to oxygen supply deficiency [18]. Moreover, the increases in Sima protein

342 levels and $O D D-G F P$ reporter expression indicate reduced internal oxygen levels (Fig 
$3432 \mathrm{~A}, 2 \mathrm{~B}$ and S3B). Finally, the bunch bouton phenotype in the trh mutant was

344 recapitulated by rearing larvae under hypoxia, and it was suppressed by rearing larvae

345 under hyperoxia. Taken together, these observations suggest that cells in the trh

346 mutant sense low oxygen levels caused by the defective tracheal system and respond

347 by elevating Sima protein levels. It is not clear how profound this effect is for other

348 types of larval cells. Based on our ODD-GFP and Sima immunostaining patterns (Fig

$3492 \mathrm{~A}, 2 \mathrm{~B}$ and S3B), many types of cells are likely to be affected [50]. Our results also

350 suggest that Trh has a late developmental role in tracheal morphogenesis, in addition

351 to its well-characterized role in early tracheal cell fate specification $[29,30]$. Unlike

352 the mammalian homologs NPAS1 and NPAS3 that function in the nervous system,

353 the Drosophila NPAS1/3 homolog Trh is more dedicated to tracheal development.

\section{Glia induce synaptic remodeling}

356 We suggest that glia is the major cell type mediating bunch bouton formation

357 in the trh mutant under hypoxia. HIF-1 $\alpha /$ Sima was ubiquitously, including glia,

358 increased in both the $t r h^{1} / t r h^{2}$ mutant and the control grown under hypoxia (Fig S3B).

359 Importantly, by manipulating Sima expression in glia we could regulate bunch bouton

360 formation (Fig 3). Elevated Sima levels induce tracheal sprouting in tracheal cells, as

361 well as protrusions in non-tracheal cells [18]. Interestingly, we also observed

362 increased overlap of glial processes with synaptic area in the trh mutant, indicative of

363 a glial response (Fig S4C, S4D). Several types of cells in Drosophila have been

364 shown to respond to hypoxia [39, 51]. For instance, under hypoxia, elevated Sima

365 levels induce the expression of Breathless (Btl, the FGF receptor) in tracheal cells that

366 branch out seeking cells that express Branchless (Bnl)/FGF, with this latter process 
367 also being partially dependent on Sima $[18,19]$. In an alternative pathway, atypical

368 soluble guanylyl cyclases that are less sensitive to nitric oxide than conventional

369 soluble guanylyl cyclases can mediate graded and immediate hypoxia responses

370 mainly in neurons $[52,53]$. Drosophila glia have not been reported to sense and

371 respond to hypoxia, but mammalian astrocytes in the central nervous system have

372 been shown to be involved in these processes. In a middle cerebral artery occlusion

373 mouse model, astrocyte activation was shown to play a crucial role in ischemic

374 tolerance, which is mediated through $\mathrm{P} 2 \mathrm{X} 7$ receptor-activated HIF-1 $\alpha$ upregulation

375 [24]. Under physiological hypoxia, reduced mitochondrial respiration leads to the

376 release of intracellular calcium and exocytosis of ATP-containing vesicles, thereby

377 signaling the brainstem to modulate animal breathing [54]. Our results reveal a role

378 for Drosophila larval glia in sensing hypoxia via the conventional HIF-1 $\alpha /$ Sima

379 pathway, warranting further detailed study.

380 We also demonstrated that under hypoxia, glia modulate the formation of 381 synaptic boutons (Fig 3). These results clearly place the glia-modulated morphology 382 of synaptic boutons in the context of hypoxia responses. Several studies have 383 suggested that glia play important roles in regulating synaptic morphology at 384 developmental stages or in response to neural insult. Perisynaptic Schwann cells 385 surround nerve terminals and express neurotransmitter receptors, modulating synaptic 386 efficacy upon nerve stimulation at mouse NMJs [55]. After nerve injury, Schwann 387 cells participate in synaptic homeostasis and remodeling during NMJ re-innervation 388 [56]. Chronic hypoxia causes hypomyelination, leading to synaptic reduction in the 389 mouse cortex, which could be rescued by genetically-induced or drug-enhanced 390 hypermyelination [57]. In Drosophila, expansion of glial structures to synaptic 391 boutons matches synaptic growth [44]. Glial invasion of the synaptic region is also 
392 suggested to clear presynaptic debris of unstable boutons during activity-dependent

393 synaptic growth [58]. Our study further establishes that in response to hypoxia, $\mathrm{Wg}$ is

394 a glial signal that modulates synaptic bouton formation. Two sources of $\mathrm{Wg}$, from

395 presynaptic motor neurons and from glia, are involved in synapse growth and

396 remodeling [40]. Our results suggest that Sima upregulates the level of $\mathrm{Wg}$ secreted

397 from glia to modulate synapse formation in the trh mutant or in control larvae grown

398 under hypoxia. In hypoxic macrophages, HIF-1 $\alpha$ mediates the induction of Wnt1,

399 which is a mammalian homolog of $\mathrm{Wg}$ [59-61]. Although it is unclear whether $\mathrm{Wg}$ is

400 a direct target of the hypoxia signal Sima in Drosophila, we show that the level of $\mathrm{Wg}$

401 is controlled by glial Sima (Fig 4C, 4D) and that it mediates Sima-induced bunch

402 bouton formation at trh NMJs (Fig 4E, 4F). As a secreted morphogen, Wg functions

403 in both pre-synaptic and post-synaptic sites [41]. At presynaptic terminals, the

404 canonical Wg pathway induces microtubule loop formation to regulate synaptogenesis

405 [43]. We also detected an increase in microtubule loops in the trh mutant (Fig S4A,

$406 \mathrm{~S} 4 \mathrm{~B})$, consistent with a role for $\mathrm{Wg}$ in mediating the hypoxia response by modulating

407 synapse formation. Postsynaptic $\mathrm{Wg}$ signaling leads to subsynaptic reticulum

408 differentiation [41], which was not apparent in the trh mutant (Fig S1D), suggesting

409 that $\mathrm{Wg}$ might be a component of the complex hypoxia response that induces synapse

410 remodeling. Brief exposure to hypoxia induces immature spines and impaired

411 synaptic function in hippocampal neurons [23]. The morphological change to bunch

412 boutons at trh NMJs (Fig 1A and 1B) was not accompanied by altered synaptic

413 transmission (Fig 7A-F), which may reflect a compensatory effect during long-term

414 hypoxia.

415 The bunch bouton phenotype has also been described in spastin mutants [34, 62]. As

416 an AAA ATPase, Spastin severs microtubules to facilitate transport to distal axon 
417 segments $[63,64]$. Accordingly, the spastin mutant also exhibits a lack of

418 microtubules at terminal boutons [62]. In contrast, the trh mutant presented an

419 increase of microtubule loops (Fig S4A, S4B). Microtubule loops have been linked to

420 synaptic bouton stabilization, and an excess of microtubule loops has been associated

421 with increased synaptic bouton formation $[65,66]$. The altered morphology of bunch

422 boutons may be part of the structural changes necessary to maintain normal synaptic

423 transmission under hypoxia. The trh and spastin mutants also exhibit differences in

424 synaptic function, with loss of spastin function slightly enhancing spontaneous

425 synaptic transmission release but reducing evoked synaptic transmission [62]. Thus,

426 although the morphology of synaptic boutons at $\operatorname{trh}$ NMJs resembles that of spastin

427 mutants, bunch boutons at trh NMJs retain synaptic functions, unlike the impaired

428 synaptic transmission of spastin mutant boutons.

\section{Difference of trh NMJs in anterior and posterior segments}

The size of NMJs in muscles 6/7 decreases from the anterior to posterior

432 segments, which could represent a coupling with muscle growth [67, 68], thereby

433 maintaining similar electrophysiological efficacy at anterior and posterior NMJs (Fig

434 7A-F). Interestingly, our findings show that synaptic responses in the trh mutant

435 differ, with bunch boutons only appearing in anterior segments (Fig 6A and 6B).

436 Furthermore, synaptic transmission at trh NMJs remained normal in anterior A3

437 segments but was impaired in posterior A6 segments (Fig 7A-F). These observations

438 are consistent with bunch bouton formation being part of a homeostatic response to

439 restore synaptic activity. Why synapses were not remodeled in posterior segments

440 remains unclear. Motor neurons in the ventral nerve cord project much longer axons 
441 to muscles in posterior segments compared to anterior ones. It has been shown that

442 axonal transport to posterior segments is more vulnerable to inefficient transport

443 conditions. For example, mutation of long-chain Acyl-CoA synthetase impairs the

444 balance between anterograde and retrograde transport, causing distally-biased axonal

445 aggregations and affecting the growth and functioning of synapses [69]. In addition,

446 larval forward locomotion, propelled by peristatic contraction, is controlled by

447 different circuits targeting anterior and posterior segments. The GABAergic SEZ-

448 LN1 neurons specifically control posterior A6 and A7 segmental muscle contraction

449 by inhibiting $\mathrm{A} 27 \mathrm{~h}$ premotor neurons, which promotes longitudinal muscle

450 contraction during larval forward crawling [70]. It is possible that glia-derived $\mathrm{Wg}$

451 signals from cell bodies located in the ventral nerve cord of the trh mutant may not be

452 efficiently transported to posterior segments during hypoxia. This polar difference in

453 synaptic activity and bouton morphology may contribute to the uncoordinated

454 peristatic movements of trh larvae. 


\section{Methods}

\section{Fly stocks}

457 All flies were reared at $25^{\circ} \mathrm{C} . w^{1118}$ was used as wild-type control and to backcross

458 with $t r h^{1}$ or $t r h^{2}$. Fly strains are as follows: $\operatorname{trh}^{2}$, elav-GALA, MHC-GALA, repo-GAL4,

459 ok371-GALA, UAS-trh, UAS-sima, and UAS-sima-RNAi from Bloomington

460 Drosophila Stock Center (BDSC); $\operatorname{trh}^{l}$ and $U A S$-wg-RNAi from Kyoto Stock Center,

461 and UAS-trh-RNAi from Vienna Drosophila Resource Center (VDRC). Also used

462 were btl-GAL4 [71], GFP-ODD [36], and the repo-cyto-GFP line

463 was generated to drive cytoplasmic GFP expression under the control of the

$4644.3 \mathrm{~kb}$ repo promoter, which recapitulates the full repo expression pattern. [72, 73]

\section{Hypoxia or hyperoxia rearing conditions}

466 Larvae in a food vial were transferred at 1 day after egg laying (AEL) to a ProOx

467 (model 110, BioSpherix, Lacona, NY) oxygen-controlled chamber. Oxygen or

468 nitrogen was infused into the chamber to a desired concentration (here, $5 \%$ or $50 \%$ ),

469 which was maintained until assay.

\section{$470 \quad$ Immunostaining}

471 The NMJ phenotypes were analyzed as previously described [74]. For live tissue

472 preparation, non-fixed larvae were dissected as previously described, before directly

473 incubating larval fillets with anti-horseradish peroxidase (HRP, 1:10) in phosphate

474 buffered saline (PBS) for 10 minutes. Primary antibodies used were against Synapsin

475 (3C11, mouse, 1:100; Developmental Studies Hybridoma Bank, DSHB), HRP-Cy5

476 (rabbit, 1:100; Jackson ImmunoResearch), Dlg (mouse, 1:100, DSHB), GluRIIA

477 (mouse, 1:100, DSHB), dPAK (rabbit, 1:1000)[75], GluRIII (rabbit, 1:1000)[76], Brp

478 (nc82, mouse, 1:100, DHSB), Sima (guinea pig, 1:1000)[77], Repo (mouse, 1:1000, 
479 DSHB), Wg (4D4, mouse, 1:10, DSHB), and Futsch (22C10, mouse, 1:100, DSHB).

480 Secondary antibodies used were anti-rabbit or -mouse 488, Cy3, or Cy5 $(1: 1000$,

481 Jackson ImmunoResearch).

482 Image acquisition and processing

483 Unless specified otherwise, NMJs in muscle 6/7 of A3 segments of wandering third-

484 instar larvae were analyzed. Confocal images were acquired via LSM510 confocal

485 microscopy (Carl Zeiss) using 40x water, 40x water immersion, or 100x oil objectives.

486 All presented images are projections of confocal z-stacks. Numbers of bunch boutons,

487 total boutons, and microtubule loops were counted manually. The

488 immunofluorescence intensities of $\mathrm{Wg}$ and $\mathrm{HRP}$, as well as the areas of GFP and HRP

489 signal, were analyzed in ImageJ. Each dot in the bar graph represents the data from a

490 single NMJ of a larva, and 8-10 NMJs from 2-5 independent experiments were pooled

491 for quantification. Embryos were acquired by means of LSM510 confocal microscopy

492 (Carl Zeiss) using a 20x objective, and were analyzed as previously described [36].

493 Each dot in the bar graph represents data from a single embryo in which fluorescence

494 was measured in at least 35 cells.

495 Electrophysiological recordings

496 Basal transmission properties were analyzed at NMJs of muscle 6/7 in specified

497 segments of wandering third-instar larvae as previously described [78], with some

498 modifications. The larval body wall was dissected in cold calcium-free HL3 solution

499 and recorded in $\mathrm{HL} 3$ solution containing $0.4 \mathrm{mM} \mathrm{CaCl}_{2}$ at room temperature.

500 Crawling behavior

501 Mid third instar larvae (feeding stage) were placed on black agar plates (2\% agar with

502 black food coloring in $25 \times 20 \mathrm{~cm}^{2}$ dishes) at room temperature for filming. Video 
503 recording by a Sony Xperia Z1 camera started after 1 min habituation and lasted for 5

504 min, and it was analyzed using Ctrax software [79]. The (x, y) positions were used to

505 calculate the crawling distance between two successive frames, and crawling speed

506 was derived by dividing total distance travelled by time. The change in angle of larvae

507 between two frames was divided by time to represent rotational speed. Our forward

508 crawling assay was a modification of a previous study [48]. Larvae were transferred

509 into a tunnel ( 1 mm width) made in $2 \%$ black agar. Specimens were video-recorded

510 for 3-10 mins using a Leica S8 APO microscope. Kymographs were constructed using

511 the MultipleKymograph plug-in for ImageJ (NIH). Only forward crawling was

512 counted, and 7-10 steps for each of ten larvae were analyzed for each genotype.

514 Acknowledgments

515 We thank S. Luschnig (Universität Münster), Y. Henry Sun (Academia Sinica), T

516 Leung (National University of Singapore), A. DiAntonio (Washington University),

517 BDSC, Kyoto Stock Center, VDRC, and DSHB for providing reagents; NPAS

518 Electrophysiology Core, Taiwan Fly Core, and Hsiu-Hwa Kao for technical support;

519 as well as Y.-J., Cheng, H. Li, V. Nithianandam and all members of C.-T. Chien's

520 laboratory for discussion and comments.

521

522 Author contributions

523 Conceptualization: Pei-Yi Chen, Yi-Wei Tsai, Cheng-Ting Chien.

524 Formal analysis: Pei-Yi Chen.

525 Funding Acquisition: Cheng-Ting Chien

526 Investigation: Pei-Yi Chen.

527 Methodology: Pei-Yi Chen, Cheng-Ting Chien. 
528 Project administration: Cheng-Ting Chien.

529 Resources: Pei-Yi Chen, Yi-Wei Tsai, Angela Giangrande, Cheng-Ting Chien.

530 Supervision: Cheng-Ting Chien.

531 Validation: Pei-Yi Chen.

532 Visualization: Pei-Yi Chen.

533 Writing - original draft: Pei-Yi Chen.

534 Writing - Review \& Editing: Pei-Yi Chen, Yi-Wei Tsai, Angela Giangrande,

535 Cheng-Ting Chien. 


\section{References}

537 1. Larrivee B, Freitas C, Suchting S, Brunet I, Eichmann A. Guidance of

538 vascular development: lessons from the nervous system. Circ Res. 2009;104(4):428-

539 41. Epub 2009/02/28. doi: 10.1161/CIRCRESAHA.108.188144. PubMed PMID:

54019246687.

541 2. Tam SJ, Watts RJ. Connecting vascular and nervous system development:

542 angiogenesis and the blood-brain barrier. Annu Rev Neurosci. 2010;33(1):379-408.

543 Epub 2010/04/07. doi: 10.1146/annurev-neuro-060909-152829. PubMed PMID:

54420367445.

545 3. Banerjee S, Bhat MA. Neuron-glial interactions in blood-brain barrier

546 formation. Annu Rev Neurosci. 2007;30:235-58. Epub 2007/05/18. doi:

547 10.1146/annurev.neuro.30.051606.094345. PubMed PMID: 17506642; PubMed

548 Central PMCID: PMCPMC2824917.

549 4. Iadecola C. Neurovascular regulation in the normal brain and in Alzheimer's

550 disease. Nat Rev Neurosci. 2004;5(5):347-60. Epub 2004/04/22. doi:

551 10.1038/nrn1387. PubMed PMID: 15100718.

552 5. Zacchigna S, Lambrechts D, Carmeliet P. Neurovascular signalling defects in

553 neurodegeneration. Nat Rev Neurosci. 2008;9(3):169-81. Epub 2008/02/07. doi:

554 10.1038/nrn2336. PubMed PMID: 18253131.

555 6. Lee DL, Atkinson HJ. Physiology of nematodes: Macmillan International

556 Higher Education; 1976.

557 7. Manning G. Development of the Drosophila tracheal system. The

558 development of Drosophila melanogaster. 1993;1:609-85.

559 8. Danjo R, Kawasaki F, Ordway RW. A tripartite synapse model in Drosophila.

560 PLoS One. 2011;6(2):e17131. Epub 2011/03/02. doi: 10.1371/journal.pone.0017131.

561 PubMed PMID: 21359186; PubMed Central PMCID: PMCPMC3040228.

5629 9. Semenza GL, Nejfelt MK, Chi SM, Antonarakis SE. Hypoxia-inducible

563 nuclear factors bind to an enhancer element located 3 ' to the human erythropoietin

564 gene. Proc Natl Acad Sci U S A. 1991;88(13):5680-4. Epub 1991/07/01. PubMed

565 PMID: 2062846; PubMed Central PMCID: PMCPMC51941. 
566 10. Wang GL, Semenza GL. Purification and characterization of hypoxia-

567 inducible factor 1. J Biol Chem. 1995;270(3):1230-7. Epub 1995/01/20. PubMed

568 PMID: 7836384.

569 11. Stroka DM, Burkhardt T, Desbaillets I, Wenger RH, Neil DA, Bauer C, et al.

570 HIF-1 is expressed in normoxic tissue and displays an organ-specific regulation under

571 systemic hypoxia. FASEB J. 2001;15(13):2445-53. Epub 2001/11/02. doi:

572 10.1096/fj.01-0125com. PubMed PMID: 11689469.

573 12. Bruick RK, McKnight SL. A conserved family of prolyl-4-hydroxylases that

574 modify HIF. Science. 2001;294(5545):1337-40. Epub 2001/10/13. doi:

575 10.1126/science.1066373. PubMed PMID: 11598268.

576 13. Jaakkola P, Mole DR, Tian YM, Wilson MI, Gielbert J, Gaskell SJ, et al.

577 Targeting of HIF-alpha to the von Hippel-Lindau ubiquitylation complex by O2-

578 regulated prolyl hydroxylation. Science. 2001;292(5516):468-72. Epub 2001/04/09.

579 doi: 10.1126/science.1059796. PubMed PMID: 11292861.

580 14. Epstein AC, Gleadle JM, McNeill LA, Hewitson KS, O'Rourke J, Mole DR, et

581 al. C. elegans EGL-9 and mammalian homologs define a family of dioxygenases that

582 regulate HIF by prolyl hydroxylation. Cell. 2001;107(1):43-54. Epub 2001/10/12.

583 PubMed PMID: 11595184.

584 15. Groulx I, Lee S. Oxygen-dependent ubiquitination and degradation of

585 hypoxia-inducible factor requires nuclear-cytoplasmic trafficking of the von Hippel-

586 Lindau tumor suppressor protein. Mol Cell Biol. 2002;22(15):5319-36. Epub

587 2002/07/09. PubMed PMID: 12101228; PubMed Central PMCID: PMCPMC133938.

588 16. Huang LE, Arany Z, Livingston DM, Bunn HF. Activation of hypoxia-

589 inducible transcription factor depends primarily upon redox-sensitive stabilization of

590 its alpha subunit. J Biol Chem. 1996;271(50):32253-9. Epub 1996/12/13. PubMed

591 PMID: 8943284.

592 17. Kallio PJ, Pongratz I, Gradin K, McGuire J, Poellinger L. Activation of

593 hypoxia-inducible factor 1alpha: posttranscriptional regulation and conformational

594 change by recruitment of the Arnt transcription factor. Proc Natl Acad Sci U S A.

595 1997;94(11):5667-72. Epub 1997/05/27. PubMed PMID: 9159130; PubMed Central

596 PMCID: PMCPMC20836.

597 18. Centanin L, Dekanty A, Romero N, Irisarri M, Gorr TA, Wappner P. Cell

598 autonomy of HIF effects in Drosophila: tracheal cells sense hypoxia and induce

599 terminal branch sprouting. Dev Cell. 2008/04/16 ed2008. p. 547-58. 
600 19. Jarecki J, Johnson E, Krasnow MA. Oxygen regulation of airway branching in

601 Drosophila is mediated by branchless FGF. Cell. 1999;99(2):211-20. Epub

602 1999/10/27. PubMed PMID: 10535739.

603 20. Ortega JA, Sirois CL, Memi F, Glidden N, Zecevic N. Oxygen Levels

604 Regulate the Development of Human Cortical Radial Glia Cells. Cereb Cortex.

605 2017;27(7):3736-51. Epub 2016/09/08. doi: 10.1093/cercor/bhw194. PubMed PMID:

606 27600849; PubMed Central PMCID: PMCPMC6075453.

607 21. O'Driscoll CM, Gorman AM. Hypoxia induces neurite outgrowth in PC12

608 cells that is mediated through adenosine A2A receptors. Neuroscience.

609 2005;131(2):321-9. Epub 2005/02/15. doi: 10.1016/j.neuroscience.2004.11.015.

610 PubMed PMID: 15708476.

611 22. Nikonenko I, Jourdain P, Muller D. Presynaptic remodeling contributes to

612 activity-dependent synaptogenesis. J Neurosci. 2003;23(24):8498-505. Epub

613 2003/09/19. PubMed PMID: 13679418.

614 23. Segura I, Lange C, Knevels E, Moskalyuk A, Pulizzi R, Eelen G, et al. The

615 Oxygen Sensor PHD2 Controls Dendritic Spines and Synapses via Modification of

616 Filamin A. Cell Rep. 2016;14(11):2653-67. Epub 2016/03/15. doi:

617 10.1016/j.celrep.2016.02.047. PubMed PMID: 26972007; PubMed Central PMCID:

618 PMCPMC4805856.

619 24. Hirayama Y, Ikeda-Matsuo Y, Notomi S, Enaida H, Kinouchi H, Koizumi S.

620 Astrocyte-mediated ischemic tolerance. J Neurosci. 2015;35(9):3794-805. Epub

621 2015/03/06. doi: 10.1523/JNEUROSCI.4218-14.2015. PubMed PMID: 25740510.

622 25. Stanco A, Pla R, Vogt D, Chen Y, Mandal S, Walker J, et al. NPAS1 represses

623 the generation of specific subtypes of cortical interneurons. Neuron. 2014;84(5):940-

624 53. Epub 2014/12/04. doi: 10.1016/j.neuron.2014.10.040. PubMed PMID: 25467980;

625 PubMed Central PMCID: PMCPMC4258152.

626 26. Pieper AA, Wu X, Han TW, Estill SJ, Dang Q, Wu LC, et al. The neuronal

627 PAS domain protein 3 transcription factor controls FGF-mediated adult hippocampal

628 neurogenesis in mice. Proc Natl Acad Sci U S A. 2005;102(39):14052-7. Epub

629 2005/09/21. doi: 10.1073/pnas.0506713102. PubMed PMID: 16172381; PubMed

630 Central PMCID: PMCPMC1216832.

631 27. Zhou S, Degan S, Potts EN, Foster WM, Sunday ME. NPAS3 is a trachealess

632 homolog critical for lung development and homeostasis. Proc Natl Acad Sci U S A. 
633 2009;106(28):11691-6. Epub 2009/07/08. doi: 10.1073/pnas.0902426106. PubMed

634 PMID: 19581591; PubMed Central PMCID: PMCPMC2710647.

635 28. Levesque BM, Zhou S, Shan L, Johnston P, Kong Y, Degan S, et al. NPAS1

636 regulates branching morphogenesis in embryonic lung. Am J Respir Cell Mol Biol.

637 2007;36(4):427-34. Epub 2006/11/18. doi: 10.1165/rcmb.2006-0314OC. PubMed

638 PMID: 17110583; PubMed Central PMCID: PMCPMC1899329.

639 29. Chung S, Chavez C, Andrew DJ. Trachealess (Trh) regulates all tracheal

640 genes during Drosophila embryogenesis. Dev Biol. 2011;360(1):160-72. Epub

641 2011/10/04. doi: 10.1016/j.ydbio.2011.09.014. PubMed PMID: 21963537; PubMed

642 Central PMCID: PMCPMC3215829.

643 30. Wilk R, Weizman I, Shilo BZ. trachealess encodes a bHLH-PAS protein that

644 is an inducer of tracheal cell fates in Drosophila. Genes Dev. 1996;10(1):93-102.

645 Epub 1996/01/01. PubMed PMID: 8557198.

646 31. Jürgens G, Wieschaus E, Wieschaus Nüsslein-Volhard C, Kluding H.

647 Mutations affecting the pattern of the larval cuticle in Drosophila melanogaster. II.

648 Zygotic loci on the third chromosome1984. 283-95 p.

649 32. Chung S, Chavez C, Andrew DJ. Trachealess (Trh) regulates all tracheal

650 genes during Drosophila embryogenesis. Developmental Biology. 2011;360(1):160-

651 72. doi: https://doi.org/10.1016/j.ydbio.2011.09.014.

652 33. Younossi-Hartenstein A, Hartenstein V. The role of the tracheae and

653 musculature during pathfinding of Drosophila embryonic sensory axons.

654 Developmental Biology. 1993;158(2):430-47.

655 34. Ozdowski EF, Gayle S, Bao H, Zhang B, Sherwood NT. Loss of Drosophila

656 melanogaster p21-activated kinase 3 suppresses defects in synapse structure and

657 function caused by spastin mutations. Genetics. 2011;189(1):123-35. Epub

658 2011/06/28. doi: 10.1534/genetics.111.130831. PubMed PMID: 21705760; PubMed

659 Central PMCID: PMCPMC3176117.

660 35. Isaac DD, Andrew DJ. Tubulogenesis in Drosophila: a requirement for the

661 trachealess gene product. Genes Dev. 1996;10(1):103-17. Epub 1996/01/01. PubMed

662 PMID: 8557189.

663 36. Misra T, Baccino-Calace M, Meyenhofer F, Rodriguez-Crespo D, Akarsu H,

664 Armenta-Calderon R, et al. A genetically encoded biosensor for visualising hypoxia

665 responses in vivo. Biol Open. 2017;6(2):296-304. Epub 2016/12/25. doi: 
666 10.1242/bio.018226. PubMed PMID: 28011628; PubMed Central PMCID:

667 PMCPMC5312090.

668 37. Centanin L, Gorr TA, Wappner P. Tracheal remodelling in response to

669 hypoxia. J Insect Physiol. 2010;56(5):447-54. Epub 2009/06/02. doi:

670 10.1016/j.jinsphys.2009.05.008. PubMed PMID: 19482033; PubMed Central PMCID:

671 PMCPMC2862287.

672 38. Wang GL, Jiang BH, Rue EA, Semenza GL. Hypoxia-inducible factor 1 is a

673 basic-helix-loop-helix-PAS heterodimer regulated by cellular O2 tension. Proc Natl

674 Acad Sci U S A. 1995;92(12):5510-4. Epub 1995/06/06. PubMed PMID: 7539918;

675 PubMed Central PMCID: PMCPMC41725.

676 39. Lavista-Llanos S, Centanin L, Irisarri M, Russo DM, Gleadle JM, Bocca SN,

677 et al. Control of the hypoxic response in Drosophila melanogaster by the basic helix-

678 loop-helix PAS protein similar. Mol Cell Biol. 2002;22(19):6842-53. Epub

679 2002/09/07. PubMed PMID: 12215541; PubMed Central PMCID: PMCPMC134029.

680 40. Kerr KS, Fuentes-Medel Y, Brewer C, Barria R, Ashley J, Abruzzi KC, et al.

681 Glial wingless/Wnt regulates glutamate receptor clustering and synaptic physiology at

682 the Drosophila neuromuscular junction. J Neurosci. 2014;34(8):2910-20. Epub

683 2014/02/21. doi: 10.1523/JNEUROSCI.3714-13.2014. PubMed PMID: 24553932;

684 PubMed Central PMCID: PMCPMC3931504.

685 41. Packard M, Koo ES, Gorczyca M, Sharpe J, Cumberledge S, Budnik V. The

686 Drosophila Wnt, wingless, provides an essential signal for pre- and postsynaptic

687 differentiation. Cell. 2002;111(3):319-30. Epub 2002/11/07. PubMed PMID:

688 12419243; PubMed Central PMCID: PMCPMC3499980.

689 42. Huang Y, Huang S, Di Scala C, Wang Q, Wandall HH, Fantini J, et al. The

690 glycosphingolipid MacCer promotes synaptic bouton formation in Drosophila by

691 interacting with Wnt. eLife. 2018;7:e38183. doi: 10.7554/eLife.38183.

692 43. Miech C, Pauer HU, He X, Schwarz TL. Presynaptic local signaling by a

693 canonical wingless pathway regulates development of the Drosophila neuromuscular

694 junction. J Neurosci. 2008;28(43):10875-84. Epub 2008/10/24. doi:

695 10.1523/JNEUROSCI.0164-08.2008. PubMed PMID: 18945895; PubMed Central

696 PMCID: PMCPMC2597682.

697 44. Brink DL, Gilbert M, Xie X, Petley-Ragan L, Auld VJ. Glial processes at the

698 Drosophila larval neuromuscular junction match synaptic growth. PLoS One. 
699 2012;7(5):e37876. Epub 2012/06/06. doi: 10.1371/journal.pone.0037876. PubMed

700 PMID: 22666403; PubMed Central PMCID: PMCPMC3362601.

701 45. Hughes CL, Thomas JB. A sensory feedback circuit coordinates muscle

702 activity in Drosophila. Mol Cell Neurosci. 2007;35(2):383-96. Epub 2007/05/15. doi:

703 10.1016/j.mcn.2007.04.001. PubMed PMID: 17498969; PubMed Central PMCID:

704 PMCPMC1978164.

705 46. Lahiri S, Shen K, Klein M, Tang A, Kane E, Gershow M, et al. Two

706 alternating motor programs drive navigation in Drosophila larva. PLoS One.

707 2011;6(8):e23180. Epub 2011/08/23. doi: 10.1371/journal.pone.0023180. PubMed

708 PMID: 21858019; PubMed Central PMCID: PMCPMC3156121.

709 47. Dixit R, Vijayraghavan K, Bate M. Hox genes and the regulation of movement

710 in Drosophila. Dev Neurobiol. 2008;68(3):309-16. Epub 2007/11/30. doi:

711 10.1002/dneu.20589. PubMed PMID: 18044732.

712 48. Heckscher ES, Lockery SR, Doe CQ. Characterization of Drosophila larval

713 crawling at the level of organism, segment, and somatic body wall musculature. $\mathrm{J}$

714 Neurosci. 2012;32(36):12460-71. Epub 2012/09/08. doi: 10.1523/JNEUROSCI.0222-

715 12.2012. PubMed PMID: 22956837; PubMed Central PMCID: PMCPMC3711835.

716 49. Semenza GL. Regulation of mammalian $\mathrm{O}_{2}$ homeostasis by hypoxia-inducible

717 factor 1. Annu Rev Cell Dev Biol. 1999;15:551-78. Epub 1999/12/28. doi:

718 10.1146/annurev.cellbio.15.1.551. PubMed PMID: 10611972.

719 50. Ke Q, Costa M. Hypoxia-inducible factor-1 (HIF-1). Mol Pharmacol.

720 2006;70(5):1469-80. Epub 2006/08/05. doi: 10.1124/mol.106.027029. PubMed PMID:

72116887934.

722 51. Arquier N, Vigne P, Duplan E, Hsu T, Therond PP, Frelin C, et al. Analysis of

723 the hypoxia-sensing pathway in Drosophila melanogaster. Biochem J. 2006;393(Pt

724 2):471-80. Epub 2005/09/24. doi: 10.1042/BJ20050675. PubMed PMID: 16176182;

725 PubMed Central PMCID: PMCPMC1360697.

726 52. Morton DB, Stewart JA, Langlais KK, Clemens-Grisham RA, Vermehren A.

727 Synaptic transmission in neurons that express the Drosophila atypical soluble

728 guanylyl cyclases, Gyc-89Da and Gyc-89Db, is necessary for the successful

729 completion of larval and adult ecdysis. J Exp Biol. 2008;211(Pt 10):1645-56. Epub

730 2008/05/06. doi: 10.1242/jeb.014472. PubMed PMID: 18456892; PubMed Central

731 PMCID: PMCPMC2424211. 
732 53. Vermehren-Schmaedick A, Ainsley JA, Johnson WA, Davies SA, Morton DB.

733 Behavioral responses to hypoxia in Drosophila larvae are mediated by atypical

734 soluble guanylyl cyclases. Genetics. 2010;186(1):183-96. Epub 2010/07/02. doi:

735 10.1534/genetics.110.118166. PubMed PMID: 20592263; PubMed Central PMCID:

736 PMCPMC2940286.

737 54. Angelova PR, Kasymov V, Christie I, Sheikhbahaei S, Turovsky E, Marina N,

738 et al. Functional Oxygen Sensitivity of Astrocytes. J Neurosci. 2015;35(29):10460-73.

739 Epub 2015/07/24. doi: 10.1523/JNEUROSCI.0045-15.2015. PubMed PMID:

740 26203141; PubMed Central PMCID: PMCPMC4510287.

741 55. Colomar A, Robitaille R. Glial modulation of synaptic transmission at the

742 neuromuscular junction. Glia. 2004;47(3):284-9. Epub 2004/07/15. doi:

743 10.1002/glia.20086. PubMed PMID: 15252818.

744 56. Kang H, Tian L, Mikesh M, Lichtman JW, Thompson WJ. Terminal Schwann

745 cells participate in neuromuscular synapse remodeling during reinnervation following

746 nerve injury. J Neurosci. 2014;34(18):6323-33. Epub 2014/05/03. doi:

747 10.1523/JNEUROSCI.4673-13.2014. PubMed PMID: 24790203; PubMed Central

748 PMCID: PMCPMC4004816.

749 57. Wang F, Yang YJ, Yang N, Chen XJ, Huang NX, Zhang J, et al. Enhancing

750 Oligodendrocyte Myelination Rescues Synaptic Loss and Improves Functional

751 Recovery after Chronic Hypoxia. Neuron. 2018;99(4):689-701 e5. Epub 2018/08/07.

752 doi: 10.1016/j.neuron.2018.07.017. PubMed PMID: 30078577; PubMed Central

753 PMCID: PMCPMC6170028.

754 58. Fuentes-Medel Y, Logan MA, Ashley J, Ataman B, Budnik V, Freeman MR.

755 Glia and muscle sculpt neuromuscular arbors by engulfing destabilized synaptic

756 boutons and shed presynaptic debris. PLoS Biol. 2009;7(8):e1000184. Epub

757 2009/08/27. doi: 10.1371/journal.pbio.1000184. PubMed PMID: 19707574; PubMed

758 Central PMCID: PMCPMC2724735.

759 59. Mori H, Yao Y, Learman BS, Kurozumi K, Ishida J, Ramakrishnan SK, et al.

760 Induction of WNT11 by hypoxia and hypoxia-inducible factor-1alpha regulates cell

761 proliferation, migration and invasion. Sci Rep. 2016;6:21520. Epub 2016/02/11. doi:

762 10.1038/srep21520. PubMed PMID: 26861754; PubMed Central PMCID:

763 PMCPMC4748282.

764 60. Swarup S, Verheyen EM. Wnt/Wingless signaling in Drosophila. Cold Spring

765 Harb Perspect Biol. 2012;4(6):a007930. Epub 2012/04/27. doi: 
766 10.1101/cshperspect.a007930. PubMed PMID: 22535229; PubMed Central PMCID:

767 PMCPMC3367557.

768 61. Ortiz-Masia D, Cosin-Roger J, Calatayud S, Hernandez C, Alos R, Hinojosa J,

769 et al. Hypoxic macrophages impair autophagy in epithelial cells through Wnt1:

770 relevance in IBD. Mucosal Immunol. 2014;7(4):929-38. Epub 2013/12/05. doi:

771 10.1038/mi.2013.108. PubMed PMID: 24301659.

772 62. Sherwood NT, Sun Q, Xue M, Zhang B, Zinn K. Drosophila spastin regulates

773 synaptic microtubule networks and is required for normal motor function. PLoS Biol.

774 2004;2(12):e429. Epub 2004/11/25. doi: 10.1371/journal.pbio.0020429. PubMed

775 PMID: 15562320; PubMed Central PMCID: PMCPMC532392.

776 63. Hazan J, Fonknechten N, Mavel D, Paternotte C, Samson D, Artiguenave F, et

777 al. Spastin, a new AAA protein, is altered in the most frequent form of autosomal

778 dominant spastic paraplegia. Nat Genet. 1999;23(3):296-303. Epub 1999/12/28. doi:

779 10.1038/15472. PubMed PMID: 10610178.

780 64. Karabay A, Yu W, Solowska JM, Baird DH, Baas PW. Axonal growth is

781 sensitive to the levels of katanin, a protein that severs microtubules. J Neurosci.

782 2004;24(25):5778-88. Epub 2004/06/25. doi: 10.1523/JNEUROSCI.1382-04.2004.

783 PubMed PMID: 15215300.

784 65. Roos J, Hummel T, Ng N, Klambt C, Davis GW. Drosophila Futsch regulates

785 synaptic microtubule organization and is necessary for synaptic growth. Neuron.

786 2000;26(2):371-82. Epub 2000/06/06. PubMed PMID: 10839356.

787 66. Franco B, Bogdanik L, Bobinnec Y, Debec A, Bockaert J, Parmentier ML, et

788 al. Shaggy, the homolog of glycogen synthase kinase 3, controls neuromuscular

789 junction growth in Drosophila. J Neurosci. 2004;24(29):6573-7. Epub 2004/07/23. doi:

790 10.1523/JNEUROSCI.1580-04.2004. PubMed PMID: 15269269.

791 67. Koch I, Schwarz H, Beuchle D, Goellner B, Langegger M, Aberle H.

792 Drosophila ankyrin 2 is required for synaptic stability. Neuron. 2008;58(2):210-22.

793 Epub 2008/04/29. doi: 10.1016/j.neuron.2008.03.019. PubMed PMID: 18439406.

794 68. Nijhof B, Castells-Nobau A, Wolf L, Scheffer-de Gooyert JM, Monedero I,

795 Torroja L, et al. A New Fiji-Based Algorithm That Systematically Quantifies Nine

796 Synaptic Parameters Provides Insights into Drosophila NMJ Morphometry. PLoS

797 Comput Biol. 2016;12(3):e1004823. Epub 2016/03/22. doi:

798 10.1371/journal.pcbi.1004823. PubMed PMID: 26998933; PubMed Central PMCID:

799 PMCPMC4801422. 
800 69. Liu Z, Huang Y, Zhang Y, Chen D, Zhang YQ. Drosophila Acyl-CoA

801 synthetase long-chain family member 4 regulates axonal transport of synaptic vesicles

802 and is required for synaptic development and transmission. J Neurosci.

803 2011;31(6):2052-63. Epub 2011/02/11. doi: 10.1523/JNEUROSCI.3278-10.2011.

804 PubMed PMID: 21307243.

805 70. Tastekin I, Khandelwal A, Tadres D, Fessner ND, Truman JW, Zlatic M, et al.

806 Sensorimotor pathway controlling stopping behavior during chemotaxis in the

807 Drosophila melanogaster larva. Elife. 2018;7. Epub 2018/11/23. doi:

808 10.7554/eLife.38740. PubMed PMID: 30465650; PubMed Central PMCID:

809 PMCPMC6264072.

810 71. Shiga Y, Tanaka-Matakatsu M, Hayashi S. A nuclear GFP/ $\beta$-galactosidase

811 fusion protein as a marker for morphogenesis in living Drosophila. Dev Growth

812 Differ. 1996;38(1):99-106.

813 72. Lee BP, Jones BW. Transcriptional regulation of the Drosophila glial gene

814 repo. Mech Dev. 2005;122(6):849-62. Epub 2005/06/09. doi:

815 10.1016/j.mod.2005.01.002. PubMed PMID: 15939231.

816 73. Laneve P, Delaporte C, Trebuchet G, Komonyi O, Flici H, Popkova A, et al.

817 The Gcm/Glide molecular and cellular pathway: new actors and new lineages. Dev

818 Biol. 2013;375(1):65-78. Epub 2013/01/02. doi: 10.1016/j.ydbio.2012.12.014.

819 PubMed PMID: 23276603.

820 74. Wang M, Chen PY, Wang CH, Lai TT, Tsai PI, Cheng YJ, et al. Dbo/Henji

821 Modulates Synaptic dPAK to Gate Glutamate Receptor Abundance and Postsynaptic

822 Response. PLoS Genet. 2016;12(10):e1006362. Epub 2016/10/14. doi:

823 10.1371/journal.pgen.1006362. PubMed PMID: 27736876; PubMed Central PMCID:

824 PMCPMC5065118.

825 75. Harden N, Lee J, Loh HY, Ong YM, Tan I, Leung T, et al. A Drosophila

826 homolog of the Rac- and Cdc42-activated serine/threonine kinase PAK is a potential

827 focal adhesion and focal complex protein that colocalizes with dynamic actin

828 structures. Mol Cell Biol. 1996;16(5):1896-908. Epub 1996/05/01. PubMed PMID:

829 8628256; PubMed Central PMCID: PMCPMC231177.

830 76. Marrus SB, Portman SL, Allen MJ, Moffat KG, DiAntonio A. Differential

831 localization of glutamate receptor subunits at the Drosophila neuromuscular junction. 
832 J Neurosci. 2004;24(6):1406-15. Epub 2004/02/13. doi: 10.1523/JNEUROSCI.1575-

833 03.2004. PubMed PMID: 14960613.

834 77. Wang CW, Purkayastha A, Jones KT, Thaker SK, Banerjee U. In vivo genetic

835 dissection of tumor growth and the Warburg effect. Elife. 2016;5:e18126. Epub

836 2016/09/02. doi: 10.7554/eLife.18126. PubMed PMID: 27585295; PubMed Central

837 PMCID: PMCPMC5030086.

838 78. Tsai PI, Kao HH, Grabbe C, Lee YT, Ghose A, Lai TT, et al. Fak56 functions

839 downstream of integrin alphaPS3betanu and suppresses MAPK activation in

840 neuromuscular junction growth. Neural Dev. 2008;3:26. Epub 2008/10/18. doi:

841 10.1186/1749-8104-3-26. PubMed PMID: 18925939; PubMed Central PMCID:

842 PMCPMC2576229.

843 79. Branson K, Robie AA, Bender J, Perona P, Dickinson MH. High-throughput

844 ethomics in large groups of Drosophila. Nat Methods. 2009;6(6):451-7. Epub

845 2009/05/05. doi: 10.1038/nmeth.1328. PubMed PMID: 19412169; PubMed Central

846 PMCID: PMCPMC2734963.

847 


\section{$848 \quad$ Figure legends}

\section{Fig 1. Bunch bouton formation at trh NMJs}

850 (A, C, E) Immunostaining images show NMJs of muscle 6/7 for Syn (green) and HRP 851 (red) in $w^{1118}, \operatorname{trh}^{1} /+$, and $\operatorname{trh}^{1} / t r h^{2}$ (A), btl-GAL4 and btl-GALA/trh-RNAi (C), and $852 U A S$ - $t r h t^{1}{ }^{1} / t r h^{2}, b t l-G A L A t r h^{1} / t r h^{2}, b t l-G A L 4 / U A S$ - $t r h t r h^{1} / t r h^{2}$ (E). Dashed squares 853 in (A) are enlarged in right panels. White arrows indicate clusters of bunch boutons. 854 Scale bars are $10 \mu \mathrm{m}$. (B, D, F) Bar graphs with data dots within each bar show 855 percentages (mean \pm standard error of mean, SEM) of bunch boutons to total boutons. (B) $w^{1118}, 0 \pm 0 \%, \mathrm{n}=10 ; \operatorname{trh}^{1} /+, 3.64 \pm 1.74 \%, \mathrm{n}=10 ; \operatorname{trh}^{1} / t r h^{2}, 18.04 \pm 3.65 \%, \mathrm{n}=$ 10. (D) trh-RNAi, $0 \pm 0 \%, \mathrm{n}=10 ;$ btl-GALA, $0 \pm 0 \%, \mathrm{n}=10 ;$ btl $>$ trh-RNAi, $8.64 \pm$ $2.81 \%, \mathrm{n}=9 ;$ elav-GALA, $0 \pm 0 \%, \mathrm{n}=10 ;$ elav >trh-RNAi, $0 \pm 0 \%, \mathrm{n}=10 ;$ repo-GALA $2.14 \pm 1.56 \%, \mathrm{n}=10 ;$ repo $>$ trh-RNAi, $0 \pm 0 \%, \mathrm{n}=10 ; M H C-G A L A, 0 \pm 0 \%, \mathrm{n}=10$ $M H C>$ trh-RNAi, $0.77 \pm 0.77 \%, \mathrm{n}=10$. (F) $U A S$ - $\operatorname{trh} \operatorname{trh}^{1} / \mathrm{trh}^{2}, 13.80 \pm 3.00 \%, \mathrm{n}=10$; $b t l-G A L 4 \operatorname{trh}^{1} / t_{r h}^{2}, 13.56 \pm 2.95 \%, \mathrm{n}=10 ; b t l-G A L 4 / U A S-t r h t^{1}{ }^{1} / t r h^{2}, 0.88 \pm 0.64 \%$,

$862 \mathrm{n}=8 .\left(\mathrm{B}\right.$, bottom panel) Total bouton numbers in $w^{1118}(74.10 \pm 4.72, \mathrm{n}=10), \operatorname{trh}^{1} /+$

$863(89.60 \pm 5.16, \mathrm{n}=10)$, and $\operatorname{trh}^{1} / \operatorname{trh}^{2}(95.00 \pm 11.21, \mathrm{n}=9)$. Statistical significance by 864 Mann-Whitney test is shown as n.s., no significance; *, p < 0.5; **, p $<0.01 ; * * *, p<$ 8650.001.

868 (A) Images of late-stage embryos of $w^{1118}, \operatorname{trh}^{1} /+$, and $t r h^{1} / t r h^{2}$ carrying the GFP$869 O D D$ reporter (top row) and $m R F P-n l s$ control (bottom row) under normoxia $\left(21 \% \mathrm{O}_{2}\right)$ 870 or hypoxia $\left(5 \% \mathrm{O}_{2}\right)$. Scale bar represents $40 \mu \mathrm{m}$. (B) Bar graphs show mean \pm SEM of 871 the GFP/RFP immunofluorescence intensity ratio $\left(w^{1118}\right.$ at $21 \% \mathrm{O}_{2}, 0.18 \pm 0.05, \mathrm{n}=6$; 
$872 w^{1118}$ at $5 \% \mathrm{O}_{2}, 0.84 \pm 0.15, \mathrm{n}=6 ; \mathrm{trh}^{1} /+$ at $21 \% \mathrm{O}_{2}, 0.09 \pm 0.02, \mathrm{n}=6 ; \mathrm{trh}^{1} / \mathrm{trh}^{2}$ at

$\left.87321 \% \mathrm{O}_{2}, 0.82 \pm 0.15, \mathrm{n}=6\right)$. Statistical significance by Mann-Whitney test is shown

874 as n.s., no significance; $* *, \mathrm{p}<0.01$; ***, $\mathrm{p}<0.001$. (C) Images of NMJs from

875 muscle 6/7 immunostained for Syn (green) and HRP (red) from $w^{1118}$ at $21 \%$ or $5 \%$

$876 \mathrm{O}_{2}$ (left panels) and $\operatorname{trh}^{1} / \mathrm{trh}^{2}$ (right panels) at $21 \%$ or $50 \% \mathrm{O}_{2}$. White arrows indicate

877 clusters of bunch boutons. Scale bar represents $10 \mu \mathrm{m}$. (D) Bar graph shows

878 percentages (mean $\pm \mathrm{SEM})$ of bunch boutons to total boutons $\left(w^{1118}\right.$ at $21 \% \mathrm{O}_{2}, 0 \pm$ $8790 \%, \mathrm{n}=10 ; w^{1118}$ at $5 \% \mathrm{O}_{2}, 8.47 \pm 1.78 \%, \mathrm{n}=10 ; \operatorname{trh}^{1} / \operatorname{trh}^{2}$ at $21 \% \mathrm{O}_{2}, 12.91 \pm 2.30 \%$, $880 \mathrm{n}=10 ; \operatorname{trh}^{1} / \operatorname{trh}^{2}$ at $\left.50 \% \mathrm{O}_{2}, 0 \pm 0 \%, \mathrm{n}=10\right)$. Statistical significance by Mann881 Whitney test is shown as ***, p $<0.001$.

\section{Fig 3. Bunch bouton induction by glial Sima at trh NMJs}

884 (A, C, E) Images showing NMJs from muscle 6/7 immunostained for Syn (green) and 885 HRP (red) in repo-GAL4, and repo-GAL4/UAS-sima (A), sima-RNAi $\operatorname{trh}^{1} / \mathrm{trh}^{2}$, repo886 GAL4 $\operatorname{trh}^{1} / \mathrm{trh}^{2}$, and repo-GAL4/sima-RNAi $\operatorname{trh}^{1} / \mathrm{trh}^{2}$ (C), sima-RNAi, repo-GAL4, and 887 repo-GAL4/sima-RNAi under hypoxia at $5 \% \mathrm{O}_{2}(\mathrm{E})$. White arrows indicate bunch 888 boutons. Scale bars represent $10 \mu \mathrm{m}$. (B, D, F) Bar graphs show percentages (mean \pm 889 SEM) of bunch boutons (B) ok371-GALAIUAS-sima, $0.31 \pm 0.31 \%, \mathrm{n}=10$; repo890 GALA/UAS-sima, $8.81 \pm 2.22 \%, \mathrm{n}=10 ; M H C-G A L 4 / U A S-\operatorname{sima}, 1.19 \pm 0.64 \%, \mathrm{n}=10$. 891 (D) sima-RNAi $\operatorname{trh}^{1} / \mathrm{trh}^{2}, 7.48 \pm 1.35 \%, \mathrm{n}=10 ;$ repo-GALA $\operatorname{trh}^{1} / \mathrm{trh}^{2}, 11.56 \pm 2.17 \%, \mathrm{n}$ $892=10 ;$ repo-GALA/sima-RNAi $\operatorname{trh}^{1} /$ trh $^{2}, 1.58 \pm 0.81 \%, \mathrm{n}=10$. (F) sima-RNAi at $5 \% \mathrm{O}_{2}$, $89311.14 \pm 2.8 \%, \mathrm{n}=11 ;$ repo-GAL4 at $5 \% \mathrm{O}_{2}, 12.65 \pm 2.66 \%, \mathrm{n}=10 ;$ repo-GALA/sima$894 R N A i$ at $5 \% \mathrm{O}_{2}, 0.45 \pm 0.45 \%, \mathrm{n}=11$. Statistical significance by one-way ANOVA 895 with Tukey's Multiple Comparison post test is shown as ***, p < 0.001 (B) or Mann896 Whitney test as n.s., no significance; **, p < 0.01; ***, p $<0.001$ (D, F). 
898 Fig 4. Wg induction from glia modulates synaptogenesis at trh NMJs

899 (A, C, E) Images showing NMJs of muscle 6/7 immunostained for Wg (green) and

$900 \mathrm{HRP}$ (red) in $w^{1118}, \operatorname{trh}^{1} /+$, and $\operatorname{trh}^{1} / \mathrm{trh}^{2}$ (A); repo-GALA, repo-GALA/sima-RNAi,

901 repo-GAL4 $\operatorname{trh}^{1} / \mathrm{trh}^{2}$, and repo-GAL4/sima-RNAi $\operatorname{trh}^{1} / \mathrm{trh}{ }^{2}$ (C); and for Syn (green)

902 and HRP (red) in wg-RNAi $\operatorname{trh}^{1} / t_{r h}^{2}$ and repo-GAL4/wg-RNAi $\operatorname{trh}^{1} / \operatorname{trh}^{2}$ (E). White

903 arrows indicate clusters of bunch boutons. Scale bars represent $10 \mu \mathrm{m}$. (B, D, F) Bar

904 graphs show averages (mean \pm SEM) of normalized Wg to HRP intensities. $w^{1118}$,

$9050.18 \pm 0.03, \mathrm{n}=8 ; \operatorname{trh}^{1} /+, 0.15 \pm 0.02, \mathrm{n}=9 ; \operatorname{trh}^{1} / \mathrm{trh}^{2}, 0.49 \pm 0.07, \mathrm{n}=9$ (B), repo-

$906 G A L 4,0.23 \pm 0.04, \mathrm{n}=11 ;$ repo-GALA/sima-RNAi, $0.25 \pm 0.02, \mathrm{n}=10 ;$ repo-GAL4

$907 \operatorname{trh}^{1} / \mathrm{trh}^{2}, 0.68 \pm 0.16, \mathrm{n}=8 ;$ repo-GALA/sima-RNAi $\operatorname{trh}^{1} / \mathrm{trh}^{2}, 0.25 \pm 0.05, \mathrm{n}=9$ (D),

908 and percentages (mean \pm SEM) of bunch boutons in $w g-R N A i \operatorname{trh}^{1} / \operatorname{trh}^{2}, 17.19 \pm$

$9093.52 \%, \mathrm{n}=8$; repo-GAL4/wg-RNAi $\operatorname{trh}^{1} / \mathrm{trh}^{2}, 0.68 \pm 0.68 \%, \mathrm{n}=11$ (F). Statistical

910 significance by Mann-Whitney test is shown as n.s., no significance; *, p < 0.05; **, p

$911<0.01 ; * * *, \mathrm{p}<0.001$

912

913 Fig 5. Impaired crawling behavior of the trh mutant

914 (A) Representative 5-minute crawling traces for $w^{1118}, t r h^{1} /+$, and $t r h^{1} / t r h^{2}$. (B) Bar

915 graphs show average speeds (mean \pm SEM in $\mathrm{mm} / \mathrm{s}$ ) for $w^{1118}, 0.64 \pm 0.09, \mathrm{n}=13$;

$916 \operatorname{trh}^{1} /+, 0.45 \pm 0.08, \mathrm{n}=12 ; \operatorname{trh}^{1} / \operatorname{trh}^{2}, 0.14 \pm 0.02, \mathrm{n}=14$, and average rotational

917 speeds (mean $\pm \mathrm{SEM}$ in degree/s) for $w^{1118}, 7.80 \pm 0.62, \mathrm{n}=13 ; \operatorname{trh}{ }^{1} /+, 9.73 \pm 1.19, \mathrm{n}$

$918=12 ; \operatorname{trh}^{1} / t^{2} h^{2}, 11.26 \pm 1.86, \mathrm{n}=14$. Statistical significance by Mann-Whitney test is

919 shown as n.s., no significance; ***, p < 0.001. (D) Kymographs show four larval

920 forward crawling strides for $w^{1118}$ and $\operatorname{trh}^{1} / t r h^{2}$. The green lines show smooth

921 transitions between successive strides, whereas orange lines show abrupt transitions. 
922 (E) Bar graph shows uncoordinated stride percentages (mean \pm SEM) in $w^{1118}(0 \pm$

$9230 \%, \mathrm{n}=10)$ and $\operatorname{trh}^{1} / \operatorname{trh}^{2}(69.22 \pm 9.57 \%, \mathrm{n}=10)$. Statistical significance by Mann-

924 Whitney test is shown as ***, p $<0.001$.

925

926 Fig 6. Selective bunch bouton formation at trh NMJs of anterior segments

927 (A) Images show NMJs of muscle 6/7 from abdominal segments A2-A6 928 immunostained for Syn (green) and HRP (red) in $w^{1118}$ and $t r h^{1} / t r h^{2}$. White arrows 929 indicate clusters of bunch boutons. Scale bar represents $10 \mu \mathrm{m}$. (B, C) Line graphs 930 show average percentages (mean \pm SEM) of (B) bunch bouton $\left(w^{1118}: \mathrm{A} 2,0 \pm 0 \%, \mathrm{n}=\right.$ $93110 ; \mathrm{A} 3,0 \pm 0 \%, \mathrm{n}=9 ; \mathrm{A} 4,0 \pm 0 \%, \mathrm{n}=10 ; \mathrm{A} 5,0 \pm 0 \%, \mathrm{n}=10 ; \mathrm{A} 6,0 \pm 0 \%, \mathrm{n}=9$ $932 \operatorname{trh}^{1} / \operatorname{trh}^{2}: \mathrm{A} 2,15.40 \pm 3.59 \%, \mathrm{n}=10 ; \mathrm{A} 3,19.80 \pm 3.09 \%, \mathrm{n}=10 ; \mathrm{A} 4,5.11 \pm 1.86 \%, \mathrm{n}$ $933=9 ; \mathrm{A} 5,0.80 \pm 0.80 \%, \mathrm{n}=10 ; \mathrm{A} 6,1.33 \pm 1.33 \%, \mathrm{n}=9)$ and total bouton numbers $934 \quad\left(w^{1118}: \mathrm{A} 2,176.60 \pm 15.00, \mathrm{n}=10 ; \mathrm{A} 3,76.11 \pm 4.77, \mathrm{n}=9 ; \mathrm{A} 4,85.80 \pm 4.13, \mathrm{n}=10\right.$ $935 \mathrm{~A} 5,66.10 \pm 5.39, \mathrm{n}=10 ; \mathrm{A} 6,40.00 \pm 3.72, \mathrm{n}=9 ; \operatorname{trh}^{1} / t r h^{2}: \mathrm{A} 2,173.20 \pm 8.76, \mathrm{n}=10$ $936 \mathrm{~A} 3,106.60 \pm 15.33, \mathrm{n}=10 ; \mathrm{A} 4,74.11 \pm 9.90, \mathrm{n}=9 ; \mathrm{A} 5,60.70 \pm 9.10, \mathrm{n}=10 ; \mathrm{A} 6$ $93733.11 \pm 3.56, \mathrm{n}=9$ ) for $w^{1118}$ (magenta lines) and $t r{ }^{1} / t r h^{2}$ (blue lines). Statistical 938 significance by Mann-Whitney test is shown as n.s., no significance; *, p < 0.05 ; ***, $939 \mathrm{p}<0.001$. (D) Images showing NMJs of muscle 6/7 immunostained for Syn (green) 940 and HRP (red) in $w g-R N A i t r h^{1} / t r h^{2}$ (top panel) and repo-GALA/wg-RNAi $\operatorname{trh}^{1} / t r h^{2}$ 941 (bottom panel) in A6. (D) Bar graph shows percentages (mean \pm SEM) of bunch

942 boutons $\left(w g-R N A i \operatorname{trh}^{1} / \mathrm{trh}^{2}, 1.60 \pm 1.60 \%, \mathrm{n}=10\right.$; repo-GAL4/wg-RNAi $\operatorname{trh}^{1} / \mathrm{trh}^{2}, 0 \pm$ $9430 \%, \mathrm{n}=10)$. Statistical significance by Mann-Whitney test is shown as n.s., no 944 significance.

945

946 Fig 7. Synaptic transmission at trh NMJs. 
947 (A, B) Representative traces of mEJPs (A) and EJPs (B) recorded from NMJs of 948 muscle 6 of segment A3 (left panels) and A6 (right panels) for $w^{1118}$ and $t r h^{1} / t r h^{2}$. The 949 scales for both mEJP and EJP traces are depicted at right. (C-F) Bar graphs show 950 averages $($ mean $\pm \mathrm{SEM})$ for $(\mathrm{C}) \mathrm{mEJP}$ amplitudes $\left(w^{1118} / \mathrm{A} 3,1.43 \pm 0.11, \mathrm{n}=10\right.$; $951 \operatorname{trh}^{1} / \operatorname{trh}^{2} / \mathrm{A} 3,1.19 \pm 0.12, \mathrm{n}=13 ; w^{1118} / \mathrm{A} 6,1.25 \pm 0.11, \mathrm{n}=9 ; \operatorname{trh}^{1} / \operatorname{trh}^{2} / \mathrm{A} 6,1.51 \pm$ $9520.20, \mathrm{n}=8)$; (D) mEJP frequencies $\left(w^{1118} / \mathrm{A} 3,1.92 \pm 0.13, \mathrm{n}=10 ; \operatorname{trh}^{1} / \operatorname{trh}^{2} / \mathrm{A} 3,2.38 \pm\right.$ $\left.9530.27, \mathrm{n}=13 ; w^{1118} / \mathrm{A} 6,2.02 \pm 0.34, \mathrm{n}=9 ; \operatorname{trh}^{1} / \operatorname{trh}^{2} / \mathrm{A} 6,1.41 \pm 0.21, \mathrm{n}=8\right) ;(\mathrm{E}) \mathrm{EJP}$ 954 amplitudes $\left(w^{1118} / \mathrm{A} 3,54.61 \pm 2.06, \mathrm{n}=10 ; \operatorname{trh}^{1} / \operatorname{trh}^{2} / \mathrm{A} 3,50.89 \pm 4.18, \mathrm{n}=13 ;\right.$ $955 w^{1118} / \mathrm{A} 6,46.24 \pm 3.71, \mathrm{n}=9 ; \mathrm{trh}^{1} / \mathrm{trh}^{2} / \mathrm{A} 6,41.64 \pm 5.71, \mathrm{n}=8$ ); and (F) quantal 956 contents (QC) calculated as EJP/mEJP $\left(w^{1118} / \mathrm{A} 3,40.23 \pm 3.33, \mathrm{n}=10 ; \operatorname{trh}^{1} / \operatorname{trh}^{2} / \mathrm{A} 3\right.$, $\left.95749.63 \pm 3.91, \mathrm{n}=13 ; w^{1118} / \mathrm{A} 6,38.90 \pm 3.75, \mathrm{n}=9 ; \mathrm{trh}^{1} / \mathrm{trh}^{2} / \mathrm{A} 6,27.88 \pm 1.53, \mathrm{n}=8\right)$.

958 Statistical significance by Mann-Whitney test is shown as n.s., no significance; *, p < $9590.05 ; * *, \mathrm{p}<0.01$.

960 


\section{Supporting information}

\section{S1 Fig. Presynaptic and postsynaptic structures in trh mutants}

963 (A) Bar graphs show percentages (mean \pm SEM) of satellite boutons to total boutons

$964 \quad\left(w^{1118}, 5.13 \pm 1.66 \%, \mathrm{n}=10 ; \operatorname{trh}^{1} /+, 0.66 \pm 0.66 \%, \mathrm{n}=10 ; \operatorname{trh}^{1} / \operatorname{trh}^{2}, 2.63 \pm 0.97 \%, \mathrm{n}\right.$

965 = 10). Statistical significance by Mann-Whitney test is shown as n.s., no significance;

$966 *, \mathrm{p}<0.5$. (B, C, D) Images showing NMJs of muscle 6/7 immunostained for Brp,

967 GluRIII, and HRP (B), GluRIIA, dPAK, and HRP (C), and Dlg and HRP (D) in $w^{1118}$,

$968 \operatorname{trh}^{1} /+$, and $\operatorname{trh}^{1} / t r h^{2}$. Scale bars are $10 \mu \mathrm{m}$.

969

970 S2 Fig. Tracheal defects in trh mutants

971 (A) A bright-field view of tracheal dorsal branches of $t r h^{1} /+$ (left top panel) and

$972 \operatorname{trh}^{1} / \mathrm{trh}^{2}$ (right top panel), and tracheal dorsal trunks of $\operatorname{trh}^{1} / \mathrm{trh}^{2}$ (bottom panels).

973 Numbers denote terminal branches, and arrows indicate a tracheal break (bottom left)

974 and a tracheal tangle (bottom right). Scale bar represents $50 \mu \mathrm{m}$. (B) Bar graph shows

975 mean \pm SEM of dorsal terminal branches $\left(\operatorname{trh}^{1} /+, 5.70 \pm 0.15, \mathrm{n}=10 ; \operatorname{trh}^{1} / \operatorname{trh}^{2}, 7.55 \pm\right.$

976 0.28, $\mathrm{n}=11$ ). (C) Bar graphs show mean \pm SEM of the GFP immunofluorescence

977 intensity $\left(w^{1118}\right.$ at $21 \% \mathrm{O}_{2}, 20.33 \pm 7.54, \mathrm{n}=6 ; w^{1118}$ at $5 \% \mathrm{O}_{2}, 79.31 \pm 17.98, \mathrm{n}=6$;

$978 \operatorname{trh}^{1} /+$ at $21 \% \mathrm{O}_{2}, 13.29 \pm 3.64, \mathrm{n}=6 ; \operatorname{trh}^{1} / \operatorname{trh}^{2}$ at $\left.21 \% \mathrm{O}_{2}, 108.2 \pm 14.70, \mathrm{n}=6\right)$. (D)

979 Bar graphs show mean \pm SEM of RFP immunofluorescence intensity $\left(w^{1118}\right.$ at $21 \% \mathrm{O}_{2}$,

$980102.00 \pm 15.55, \mathrm{n}=6 ; w^{1118}$ at $5 \% \mathrm{O}_{2}, 109.60 \pm 13.12, \mathrm{n}=6 ; \operatorname{trh}^{1} /+$ at $21 \% \mathrm{O}_{2}$

$981 \quad 143.00 \pm 15.67, \mathrm{n}=6 ; \operatorname{trh}^{1} / \operatorname{trh}^{2}$ at $\left.21 \% \mathrm{O}_{2}, 151.50 \pm 16.77, \mathrm{n}=6\right)$. Statistical

982 significance by Mann-Whitney test is shown as n.s., no significance; **, p < 0.01; ***,

$983 \mathrm{p}<0.001$.

984 
985 S3 Fig. Efficiency of sima-RNAi knockdown and Sima upregulation

986 (A) Assay for sima mRNA levels in da-GAL4 (control) or da-GALA/sima-RNAi shows

987 a reduction upon sima-RNAi knockdown. The Rpl19 mRNA levels are comparable in

988 both genotypes. (B) Images showing central nerve cord immunostained for Sima

989 (green) and Repo (red) in $w^{1118}$ at $21 \% \mathrm{O}_{2}, w^{1118}$ at $5 \% \mathrm{O}_{2}$, and $\operatorname{trh}^{1} / t r h^{2}$ at $21 \% \mathrm{O}_{2}$.

990 Arrows indicate glia with high Sima protein levels. Scale bar represents $20 \mu \mathrm{m}$.

991

992 S4 Fig. Microtubule loops and glial invasion of trh NMJs

993 (A) Images showing NMJs of muscle 6/7 immunostained for HRP (red) and Futsch 994 (green) in $\operatorname{trh}^{1} /+$ and $\operatorname{trh}^{1} / \operatorname{trh}^{2}$. White arrows indicate microtubule loops. Dashed 995 squares are enlarged in right panels. Scale bar represents $10 \mu \mathrm{m}$. (B) Bar graphs show 996 averages (mean \pm SEM) of Futsch loops $\left(\operatorname{trh}^{1} /+, 2.92 \pm 0.29, \mathrm{n}=12 ; \mathrm{trh}^{1} / \mathrm{trh}^{2}, 9.56 \pm\right.$ $9971.11, \mathrm{n}=9$ ). (C) 3D images of live tissues showing NMJs of muscle 6/7 carrying 998 repo-cyto-GFP (green) labeled for HRP (red) in $t r h^{l} /+$ and $t r h^{l} / t r h^{2}$ by using Imaris. 999 Synaptic overlap by glia is represented in yellow. Scale bar represents $10 \mu \mathrm{m}$. (D) Bar 1000 graph shows percentages (mean \pm SEM) of synaptic areas overlapping with glia in $1001 \operatorname{trh}^{1} /+, 6.2 \pm 0.99 \%, \mathrm{n}=10 ; \operatorname{trh}^{1} / t r h^{2}, 16.7 \pm 3.66, \mathrm{n}=10$. Statistical significance by 1002 Mann-Whitney test is shown as *, p $<0.05$ or ***, p $<0.001$.

1003

1004 S1 Movie. Forward crawling of $w^{1118}$

1005

1006 S2 Movie. Forward crawling of $\operatorname{trh}^{1} / t r h^{2}$ 
certified by peer review) is the author/funder, who has granted bioRxiv a license to display the preprint in perpetuity. It is made available $u$

Fig. 1 aCC-BY 4.0 International license.
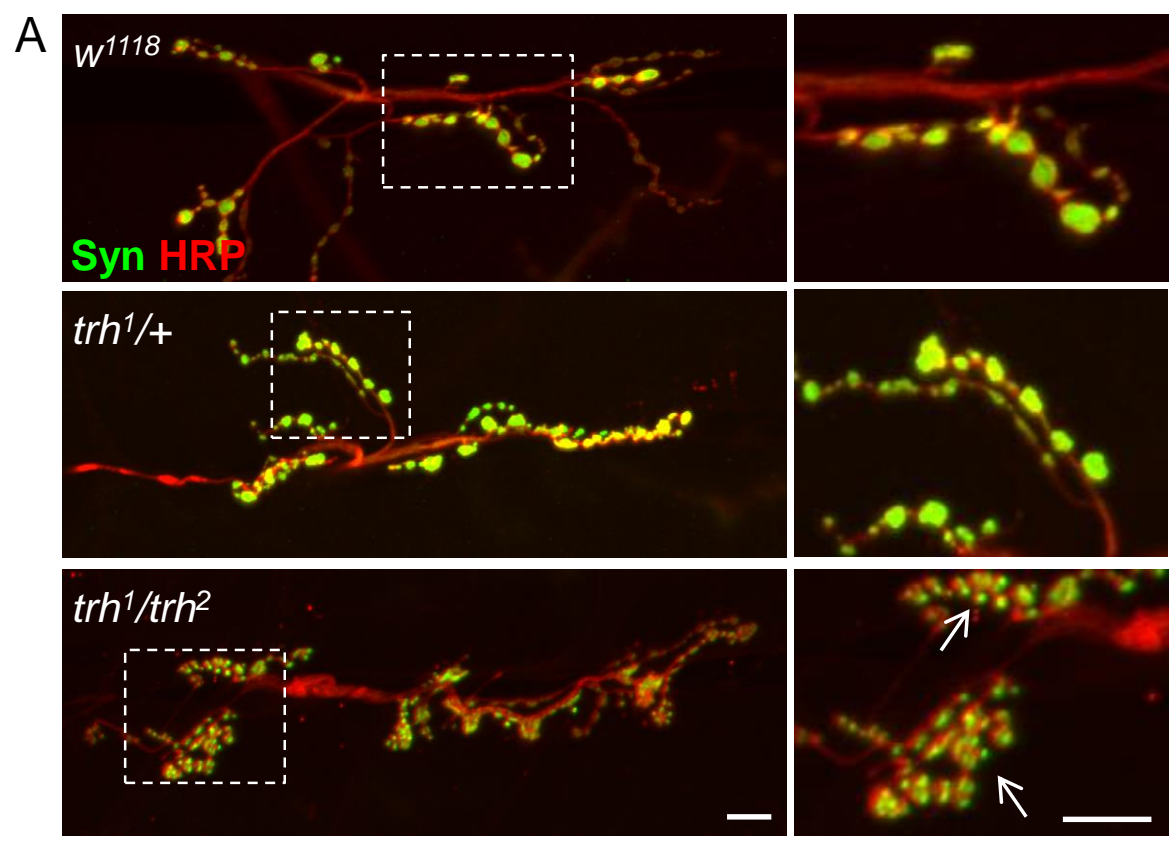

$\mathrm{B}$
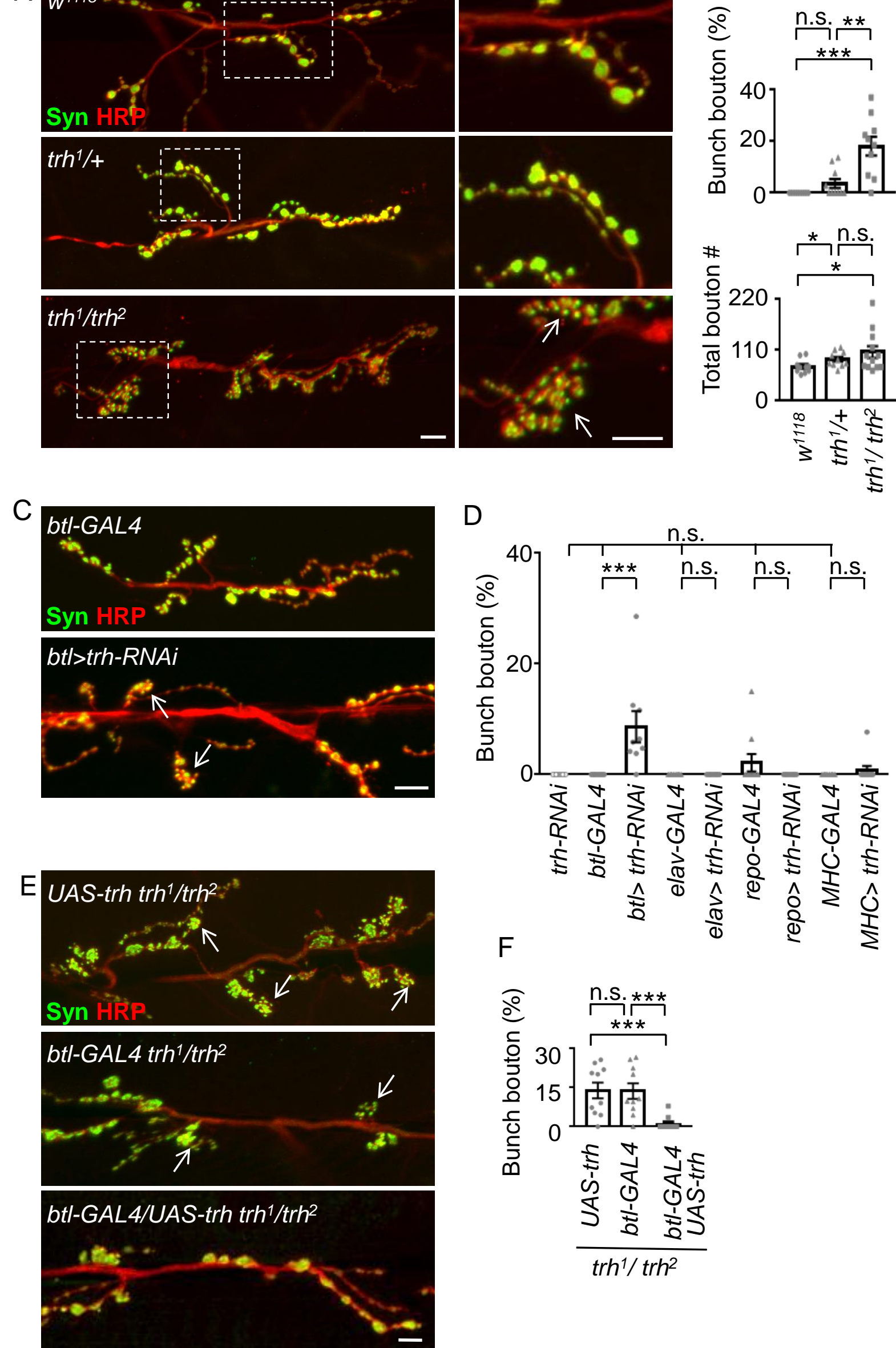

F
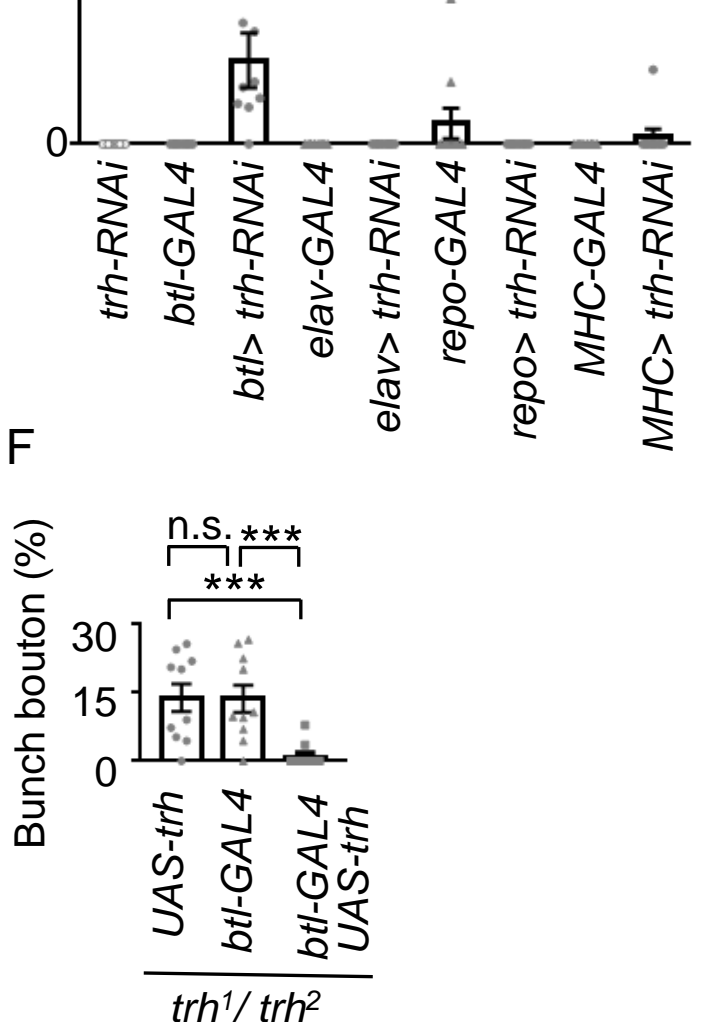
certified by peer review) is the author/funder, who has granted bioRxiv a license to display the preprint in perpetuity. It is made available u

Fig. 2 aCC-BY 4.0 International license.

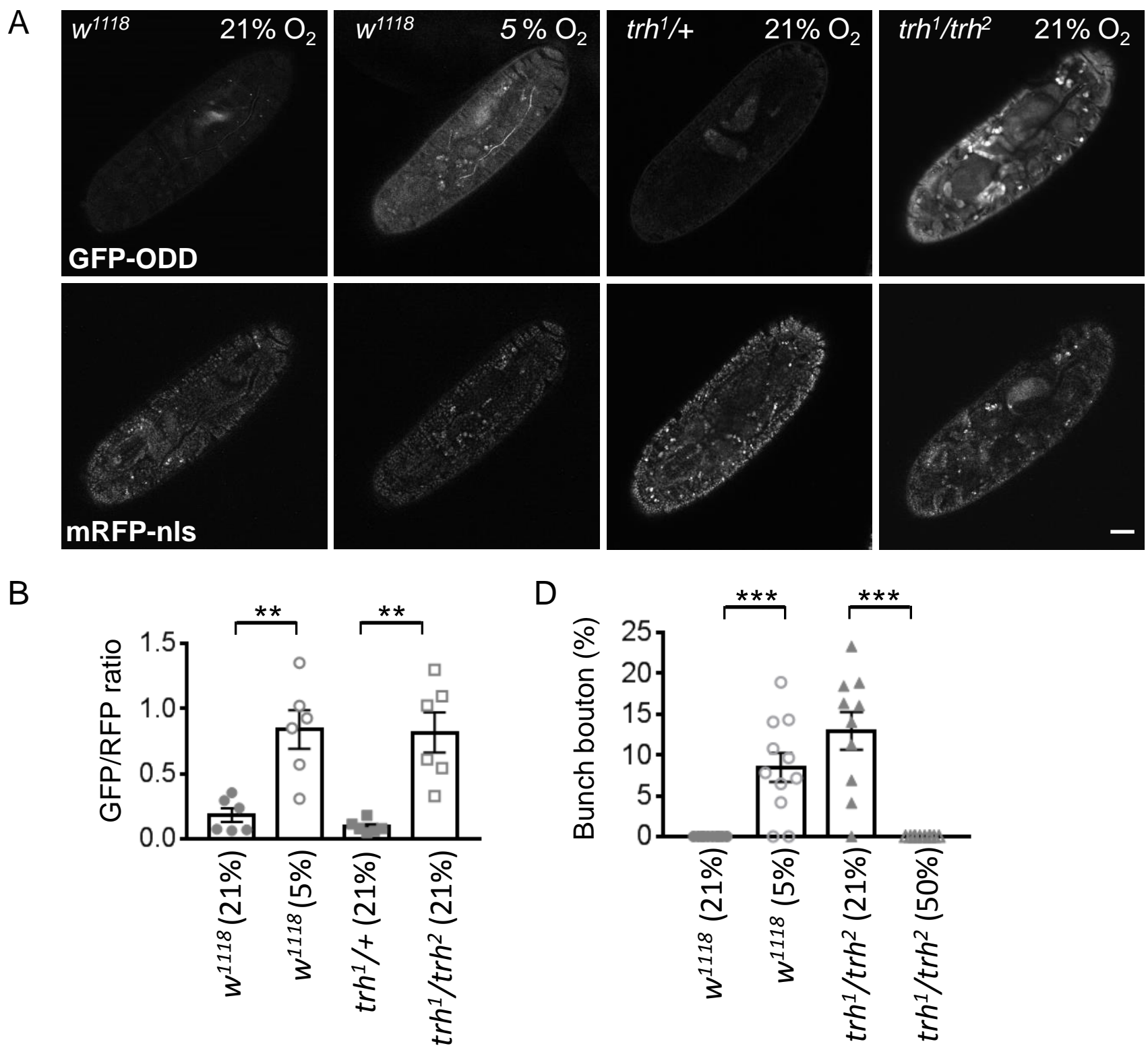

C
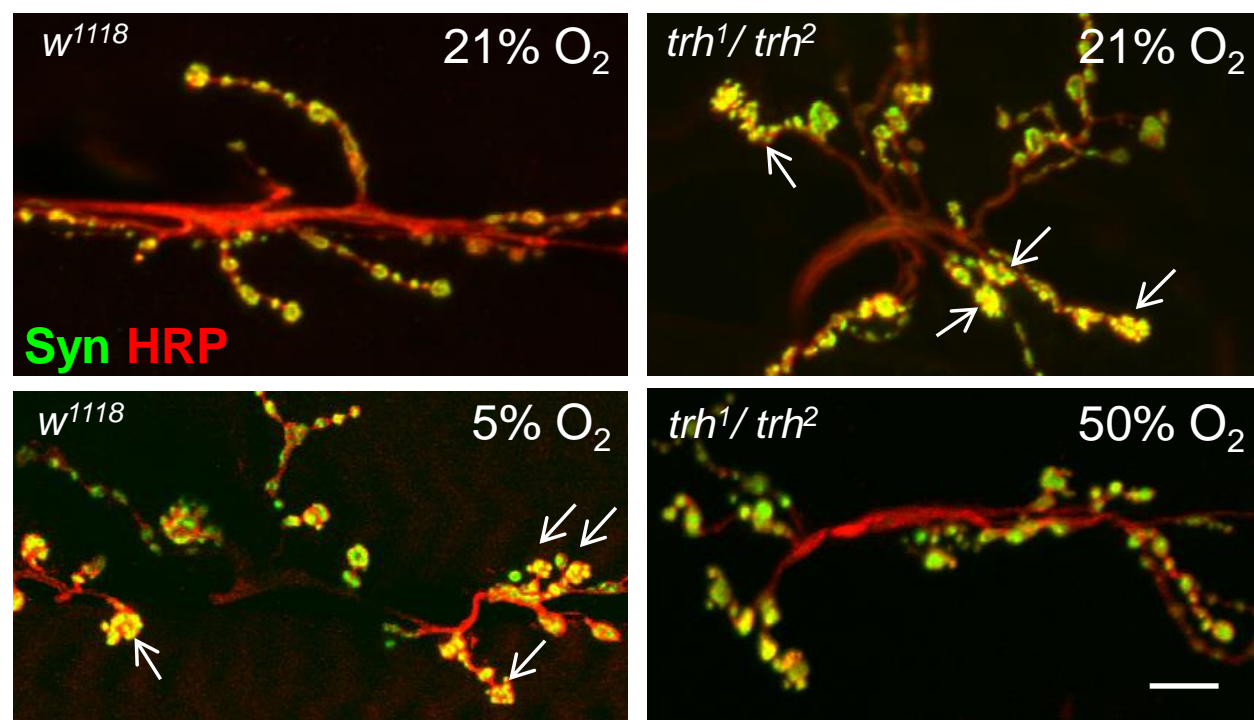


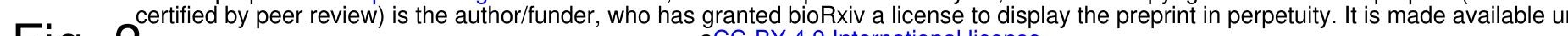

Fig. 3
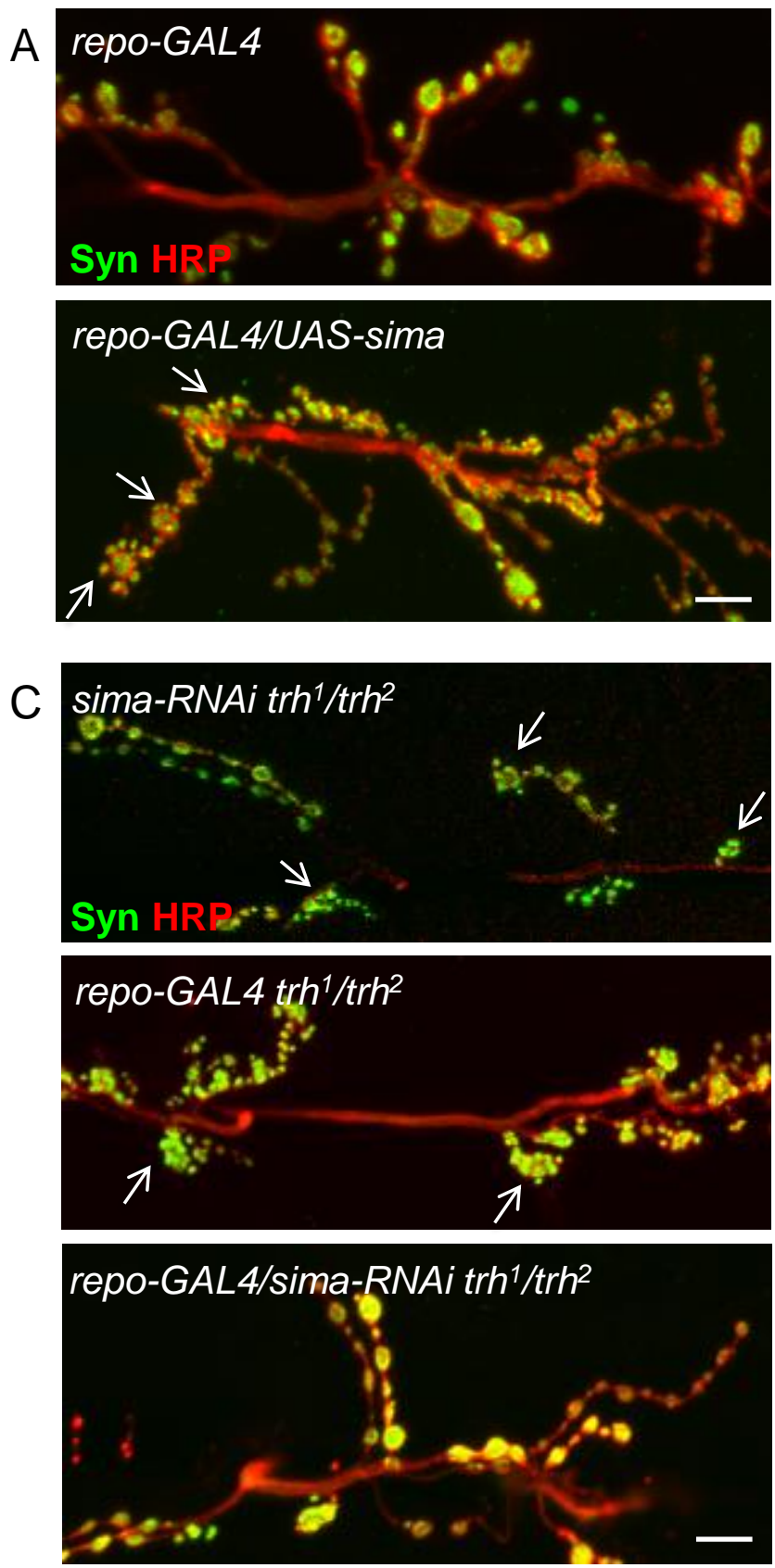

D

1. sima-RNAi trh $1 / \mathrm{trh}^{2}$

2. repo-GAL4 trh $1 / \mathrm{trh}^{2}$

3. repo-GAL4/sima-RNAi $\mathrm{trh}^{1} / \mathrm{trh}^{2}$

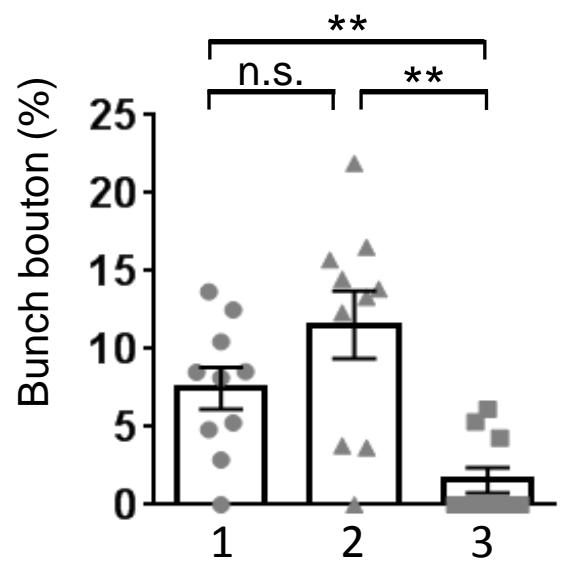

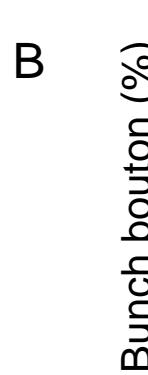

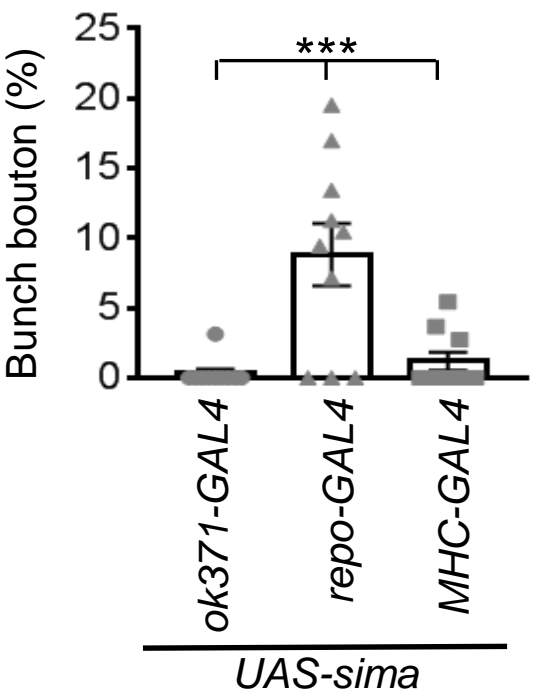

E
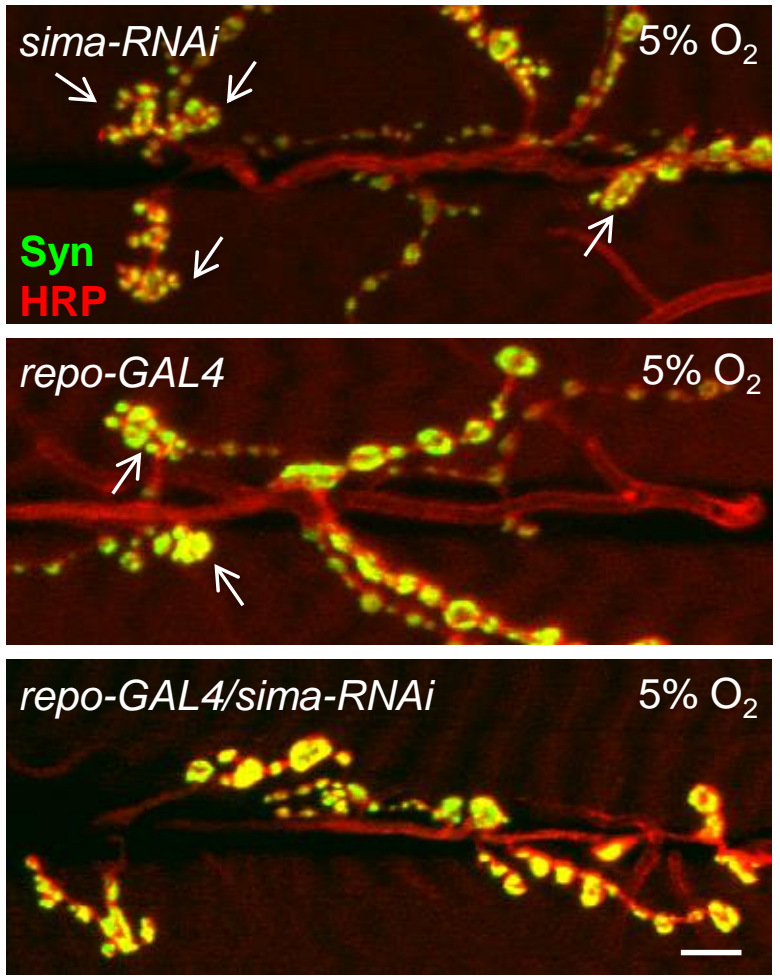

F

1. sima-RNAi $\left(5 \% \mathrm{O}_{2}\right)$

2. repo-GAL4 $\left(5 \% \mathrm{O}_{2}\right)$

3. repo-GAL4/sima-RNAi $\left(5 \% \mathrm{O}_{2}\right)$

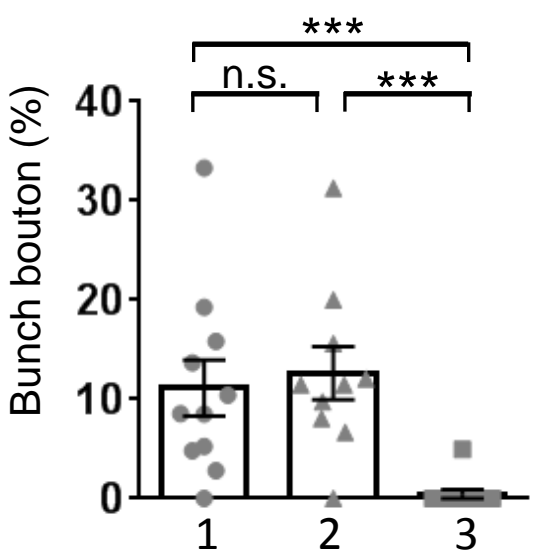


certified by peer review) is the author/funder, who has granted bioRxiv a license to display the preprint in perpetuity. It is made available u

Fig. 4 aCC-BY 4.0 International license.

A

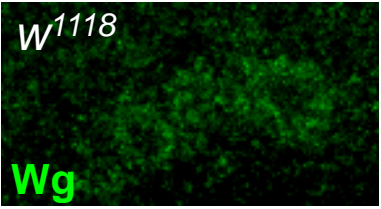

C

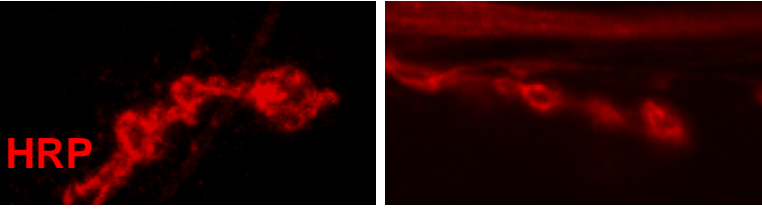

repo-GAL4

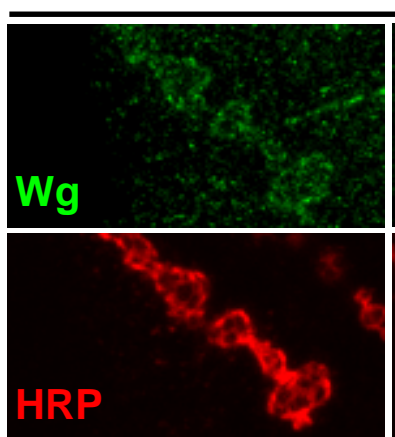

D
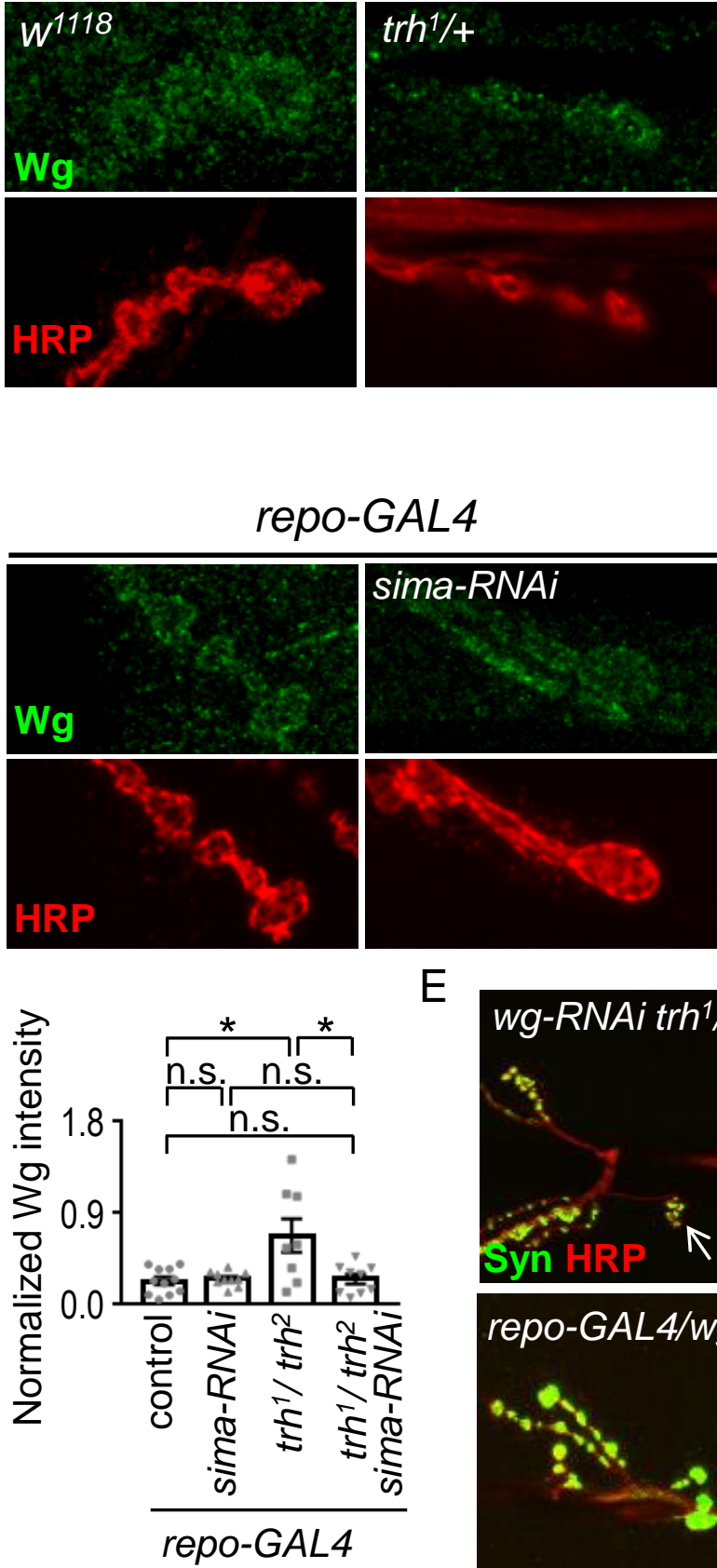

sima-RNAi

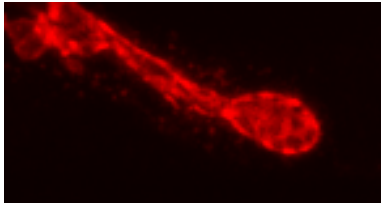

$\mathrm{E}$
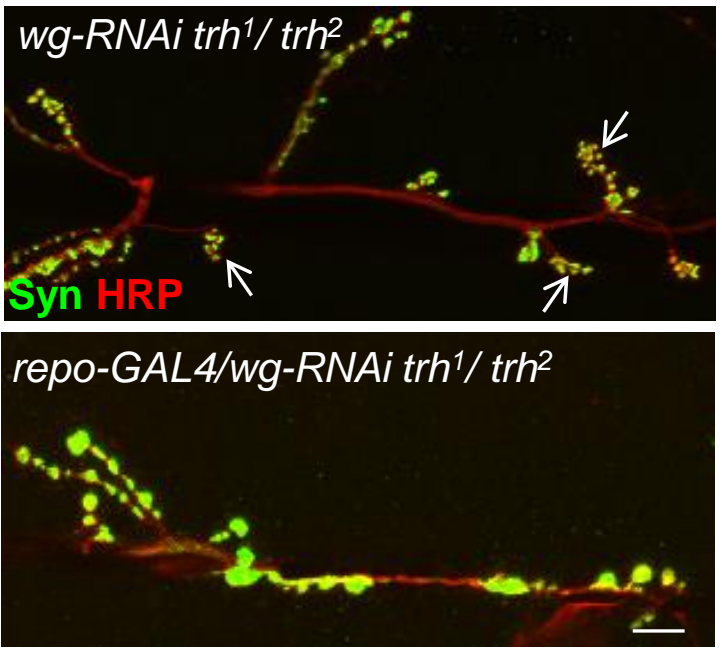

B

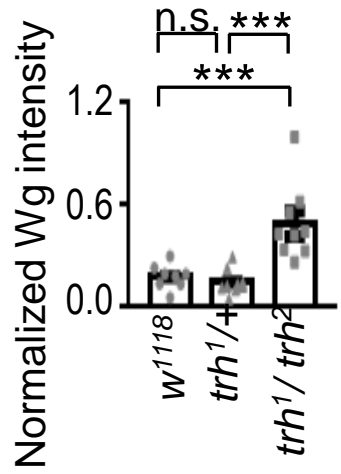

repo-GAL4 trh ${ }^{1} / \mathrm{trh}^{2}$

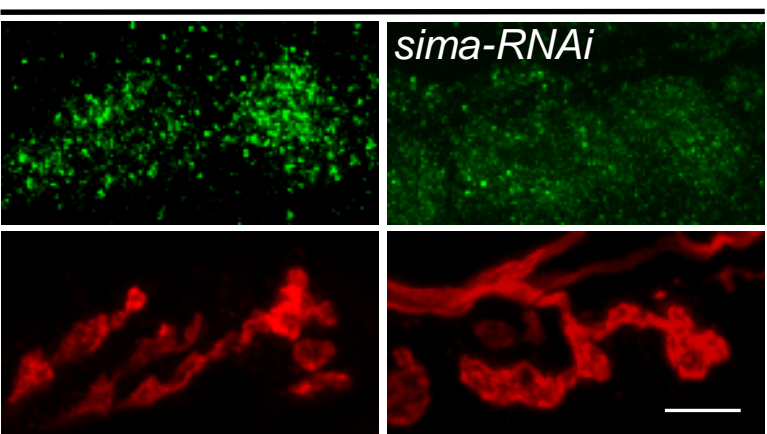

$\mathrm{F}$

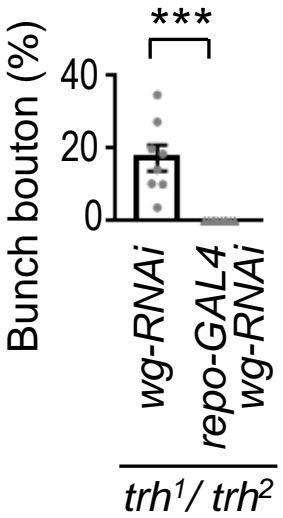


certified by peer review) is the author/funder, who has granted bioRxiv a license to display the preprint in perpetuity. It is made available u

Fig. 5

A

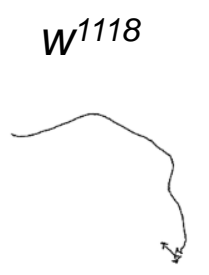

$\operatorname{trh}^{1 /+}$

$\operatorname{trh}^{1} / \mathrm{trh}^{2}$

B

C
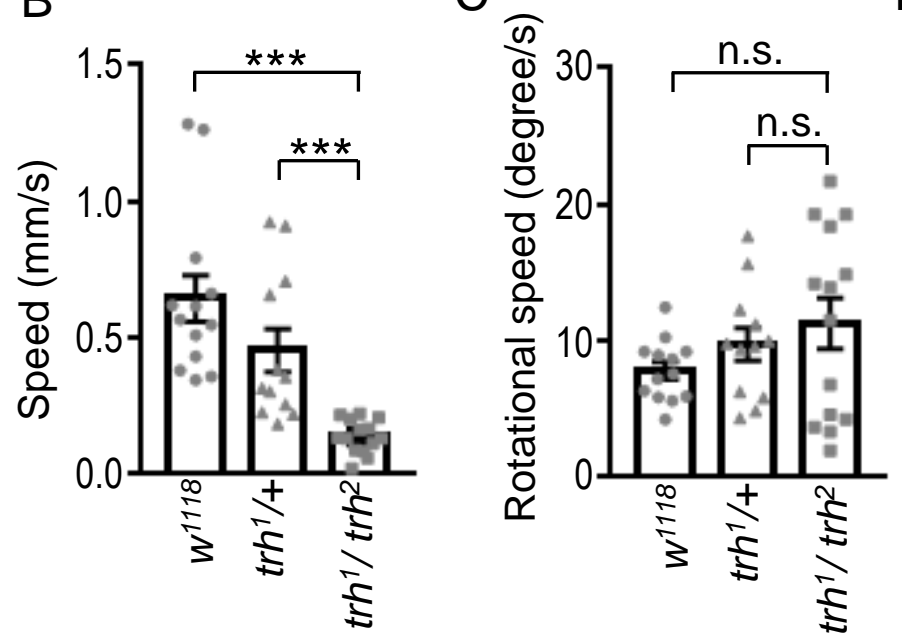

E

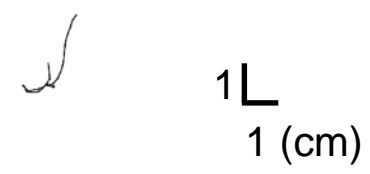

D
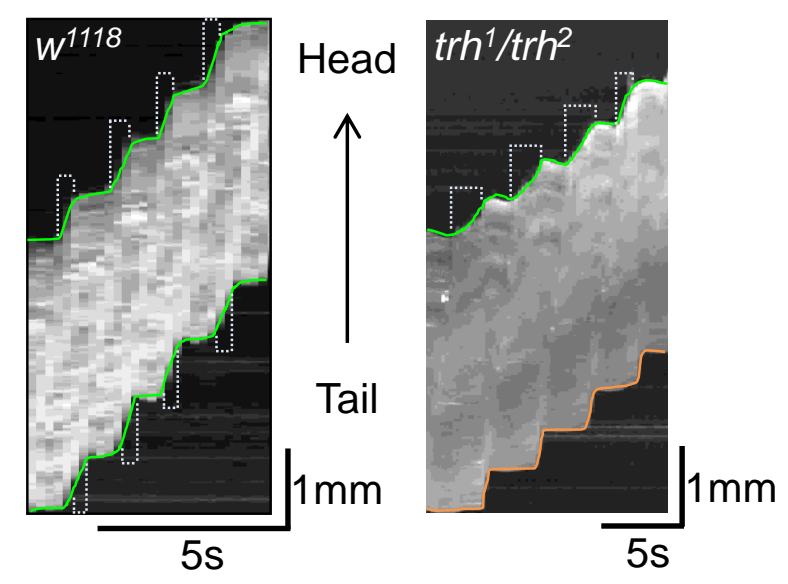
certified by peer review) is the author/funder, who has granted bioRxiv a license to display the preprint in perpetuity. It is made available $u$

Fig. 6 aCC-BY 4.0 International license.
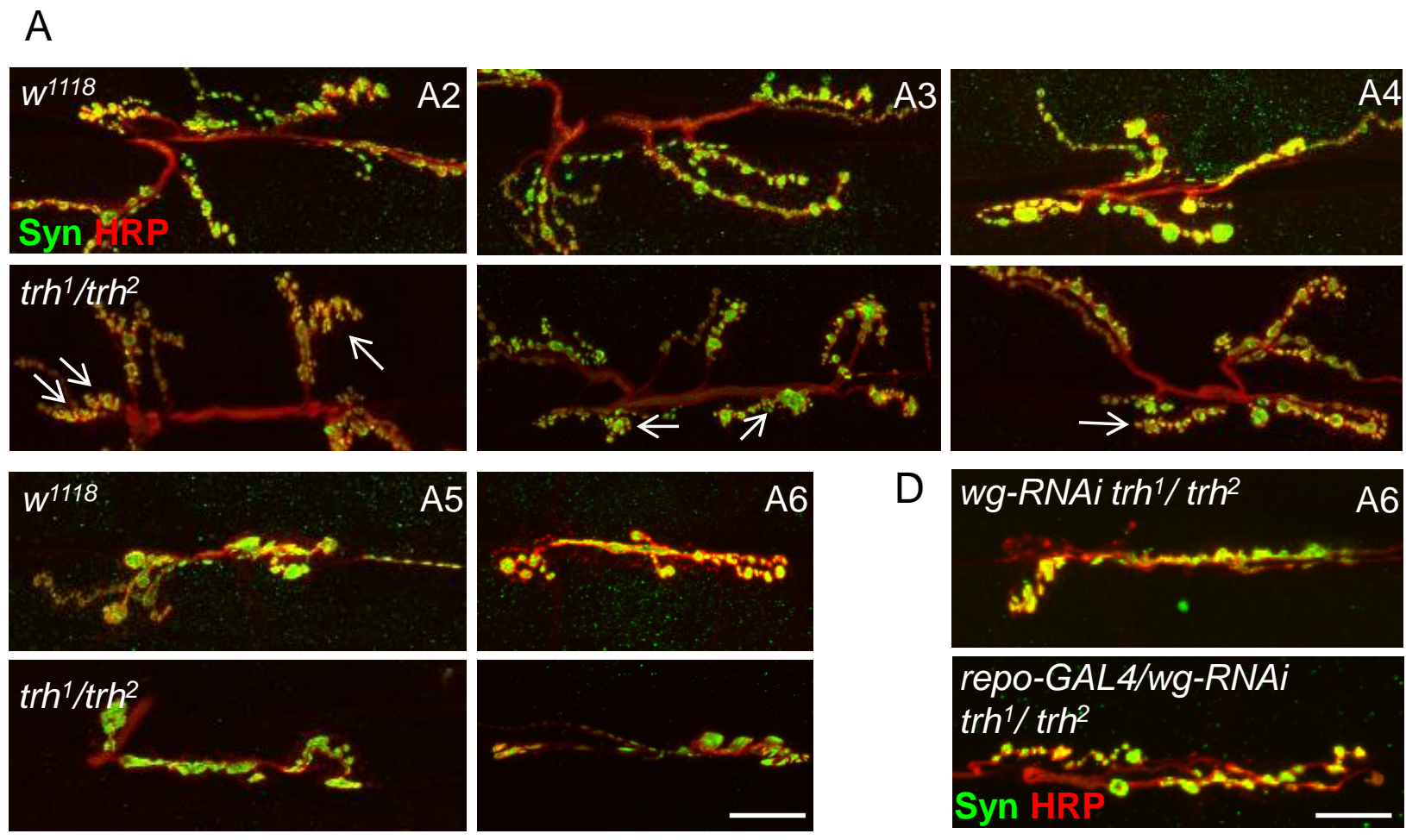

D
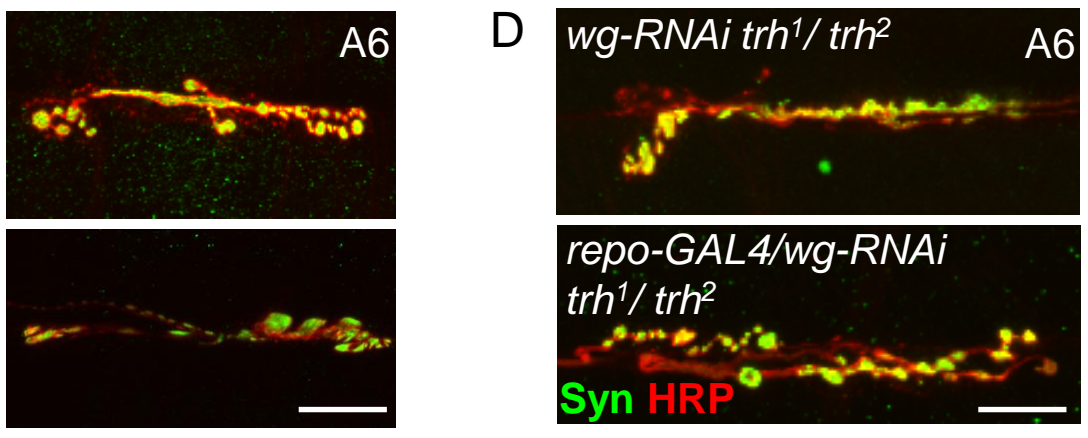

B

C

E
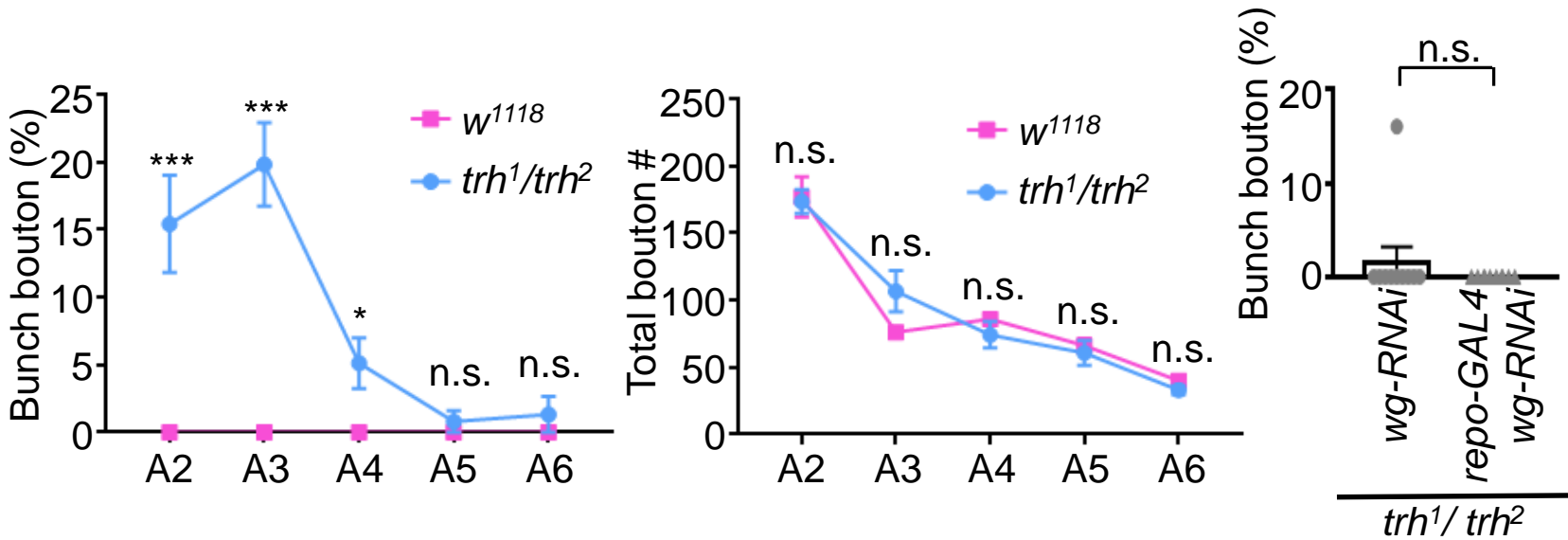


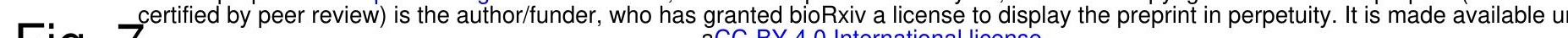

Fig. 7 aCC-BY 4.0 International license.

A

$$
w^{1118}(\mathrm{~A} 3)
$$

$w^{1118}(\mathrm{~A} 6)$

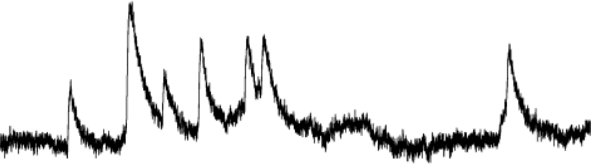

$\operatorname{trh}^{1 / t r h}{ }^{2}(\mathrm{~A} 3)$

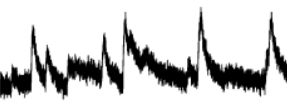

B

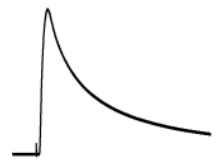

$W^{1118}(\mathrm{~A} 3)$

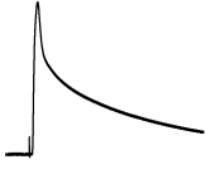

$\operatorname{trh}^{1} / \operatorname{trh}^{2}(\mathrm{~A} 3)$

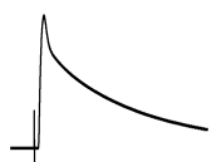

$W^{1118}(\mathrm{~A} 6)$ $\operatorname{trh}^{1} / \operatorname{trh}^{2}(\mathrm{~A} 6)$
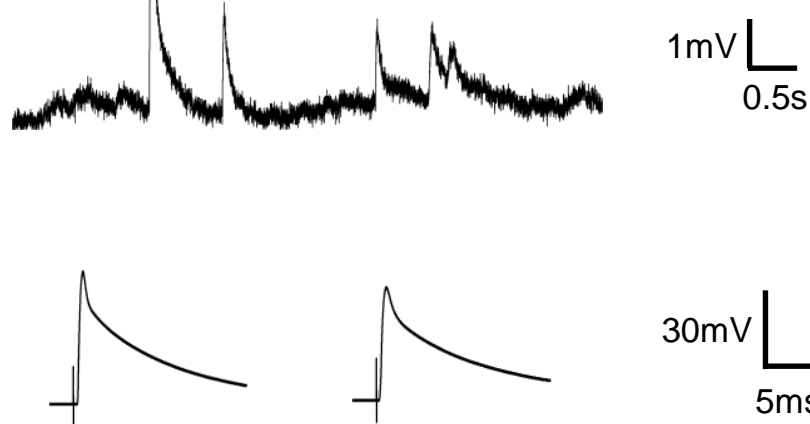

$30 \mathrm{mv} \underset{5 \mathrm{~ms}}{\longleftarrow}$
C

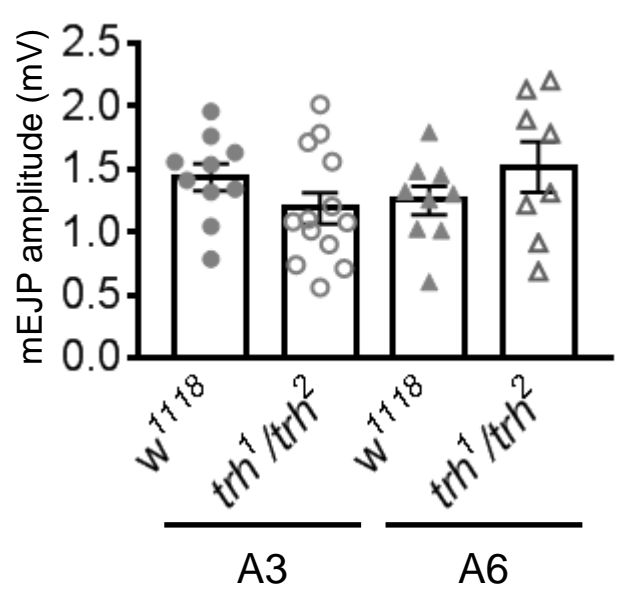

E

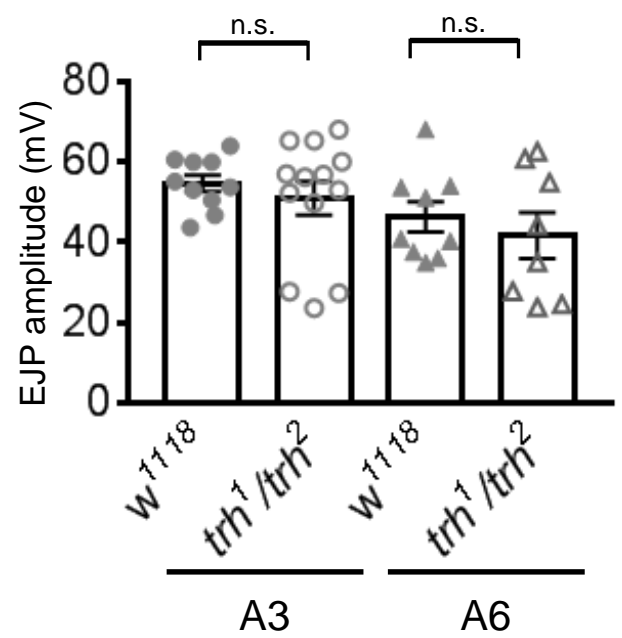

D

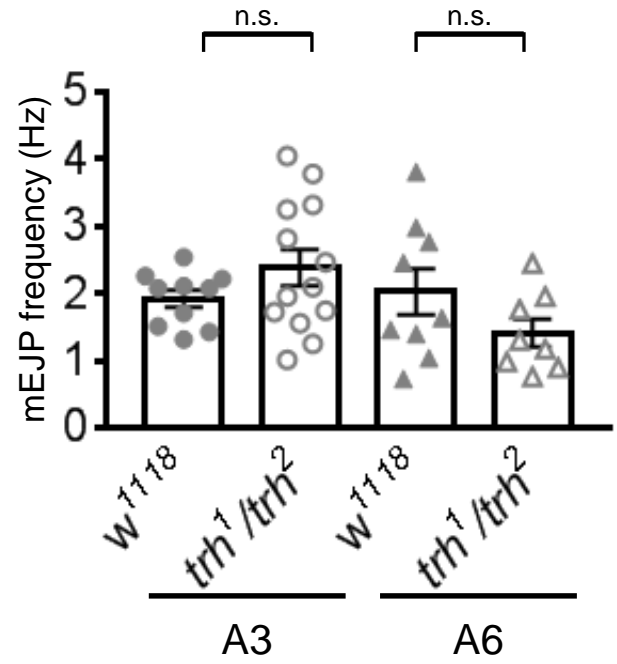

F

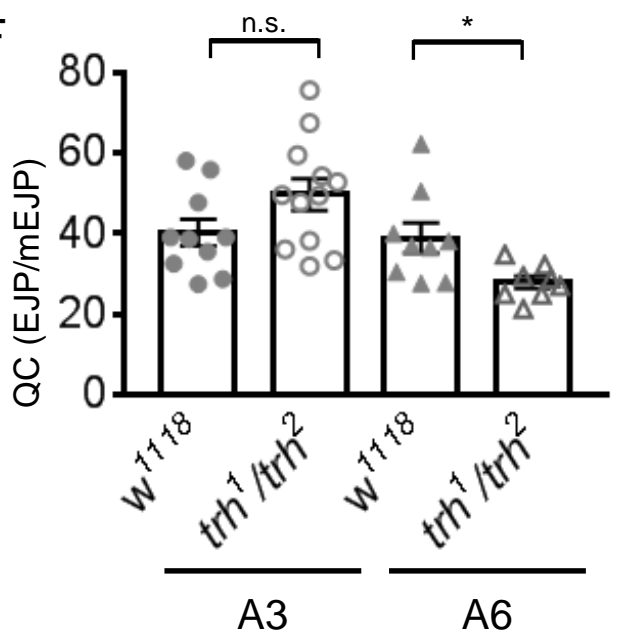

